\title{
Class I histone deacetylase inhibitor suppresses vasculogenic mimicry by enhancing the expression of tumor suppressor and anti-angiogenesis genes in aggressive human TNBC cells
}

\author{
APARNA MAITI ${ }^{1,2}$, QIANYA QI ${ }^{3}$, XUAN PENG $^{3}$, LI YAN $^{3}$, KAZUAKI TAKABE $^{1}$ and NITAI C. HAIT ${ }^{1,2}$ \\ ${ }^{1}$ Division of Breast Surgery, Department of Surgical Oncology, ${ }^{2}$ Department of Molecular and Cellular Biology, and \\ ${ }^{3}$ Department of Biostatistics and Bioinformatics, Roswell Park Comprehensive Cancer Center, Buffalo, NY 14263, USA
}

Received November 6, 2018; Accepted April 17, 2019

DOI: $10.3892 /$ ijo.2019.4796

\begin{abstract}
Triple-negative breast cancer (TNBC) cells form angiogenesis-independent vessel-like structures to survive, known as vasculogenic mimicry (VM), contributing to a poor prognosis for cancer patients. Nuclear localized class I histone deacetylases (HDACs) enzymes, particularly HDACs 1, 2, 3 deacetylate chromatin histones, are overexpressed in cancers and epigenetically regulate the expression of genes involved in cancer initiation and progression. The specific HDAC inhibitor, entinostat, has been shown to attenuate tumor progression and metastasis in TNBC. In this study, we hypothesized that entinostat would enhance the expression of anti-angiogenic and tumor suppressor genes and would thus suppress VM structures in TNBC cells in a 3D Matrigel cell culture preclinical model. Our data indicated that invasive triple-negative MDA-MB-231, LM2-4 and BT-549 breast cancer cells, but not poorly invasive luminal MCF-7 cells, efficiently underwent matrix-associated VM formation. Approximately $80 \%$ of TNBC cells with the stem cell phenotype potential formed vessel-like structures when mixed with Matrigel and cultured in the low attachment tissue culture plate. The molecular mechanisms of VM formation are rather complex, while angiogenesis inhibitor genes are downregulated and pro-angiogenesis genes are upregulated in VM-forming cells. Our data revealed that treatment of the TNBC VM phenotype cells with entinostat epigenetically led to
\end{abstract}

Correspondence to: Dr Nitai Hait, Division of Breast Surgery, Department of Surgical Oncology, Roswell Park Comprehensive Cancer Center, Elm and Carlton Streets, Buffalo, NY 14263, USA

E-mail: nitai.hait@roswellpark.org

Abbreviations: TNBC, triple-negative breast cancer; ER, estrogen receptor; VM, vasculogenic mimicry; HDAC, histone deacetylase; EMT, epithelial-mesenchymal transition; CSC, cancer stem cell; PTEN, phosphatase and tensin homolog; PCR, polymerase chain reaction; RT-qPCR, reverse transcription-quantitative PCR; OS, overall survival

Key words: vasculogenic mimicry, triple-negative breast cancer, histone deacetylase inhibitor the re-expression of the anti-angiogenic genes, serpin family $\mathrm{F}$ member 1 (SERPINF1) and thrombospondin 2 (THBS2), and to that of the tumor suppressor genes, phosphatase and tensin homolog (PTEN) and p21, and reduced VM structures. We also found that treatment of the TNBC VM phenotype cells with entinostat downregulated the expression of vascular endothelial growth factor A (VEGF-A), and that of the epithelial-mesenchymal transition (EMT)-related genes, Vimentin and $\beta$-catenin. METABIRC and TCGA breast cancer cohort mRNA expression data analysis revealed that a high expression of the anti-angiogenesis-associated genes, THBS2, SERPINF1 and serpin family B member 5 (SERPINB5), and of the tumor suppressor gene, PTEN, was associated with a better overall survival (OS) of breast cancer patients. Taken together, the findings of this study demonstrate that HDACs 1,2,3 partly contribute to VM formation in TNBC cells; thus, HDACs may be an important therapeutic target for TNBC.

\section{Introduction}

Solid tumors depend on vascular networks for the supply of blood, oxygen and nutrients. The ability of solid tumors to initiate and sustain angiogenesis is a cancer hallmark (1). Over the past decades, the development of angiogenesis inhibitors has improved cancer therapies for patients and anti-angiogenic drugs are widely used in the treatment of many solid tumors $(2,3)$. However, in many cases, successful initial responses are followed by the acquisition of resistance to anti-angiogenesis and eventually, this leads to tumor recurrence. A number of strategies have been considered to explain the reasons for tumor recurrence. In 1999, Maniotis et al (4) introduced the angiogenic independent pathway of the blood supply system and feeding tumor cells, which involves a phenotypic switch of cancer cells within a tumor that modify their morphology to form a net-like fluid-conducting tubular structures, a process known as vasculogenic mimicry (VM) $(4,5)$. The tube-like structures are not true blood vessels, but merely mimic the function of vessels, thereby clearly defining the phenomenon of VM (4,6-10). Following its initial discovery, it was considered that the neovascularization mechanism is the characteristic of aggressive melanomas; however, VM has also reported in a number of other non-melanoma neoplastic malignancies, 
such as breast (11), ovarian (12,13), prostate (14) and lung (15) cancer, as well as in glioblastoma (GBM) (16). Tumor cells capable of VM formation share the common pathways of a stem cell-like, trans-endothelial phenotype, shown to be induced by hypoxia $(10,17)$. Therefore, understating the molecular mechanisms of VM formation may have important therapeutic implications in metastatic cancer.

Triple-negative breast cancers (TNBCs) account for approximately 10 to $20 \%$ of all breast cancers and are characterized by the lack of expression of estrogen receptor (ER), progesterone receptor (PR) and human epidermal growth factor receptor 2 (HER2) (18). This subtype of breast cancer is aggressive with high recurrence, metastasis and mortality rates (19), does not respond to hormonal therapies and has limited treatment options. Anti-angiogenic therapies have failed to lead to a substantial improvement in the survival of patients with TNBC (20). In mouse models, anti-angiogenic treatment has been shown to promote TNBC invasion via VM formation (21).

VM structures in patients with breast cancer are associated with a poor prognosis (22). The intrinsic heterogeneity and stem cell properties of TNBCs may render them able to form VM and metastasize to distal organs $(18,23)$. The molecular signature of the tumor cell VM phenotype has revealed the upregulated expression of genes associated with embryonic progenitors, endothelial cells, vessel formation, matrix remodeling and epithelial-mesenchymal transition (EMT), as well as the downregulation of genes predominantly associated with the inhibition of angiogenesis-related genes, including serpin family $\mathrm{F}$ member 1 (SERPINF1) and the extracellular matrix (ECM)-binding protein, thrombospondin 2 (THBS2) (9,10,24-29). Tumor suppressors, including p21, phosphatase and tensin homolog (PTEN), adenomatous polyposis coli (APC), serpin family B member 5 (SERPINB5/Maspin) genes are predominantly downregulated more often by epigenetic mechanisms in aggressive human cancers (30-33).

Therefore, the use of epigenetic drugs may be an effective strategy with which to re-express tumor suppressor and angiogenesis inhibitor genes in order to abolish VM-dependent cancers. Over the past several years of research, it has been found that epigenetic alterations also play an important role in tumorigenesis, apart from genetic aberrations. The acetylation and deacetylation of histones play a significant role, contributing to the epigenetic regulation of gene expression. Acetylated histones and non-histone proteins are targeted for deacetylation by the group of histone deacetylase (HDACs) enzymes, important in cancer progression. Class I HDACs, particularly nuclear localized HDACs 1,2,3 are overexpressed in breast cancer, are involved in cancer progression, and have emerged as promising targets in cancer therapeutics. Entinostat (MS-275) has been found to be an inhibitor of class I enzymes, with a high affinity for HDACs 1, 2 and 3 activities, but is a relatively weak inhibitor of HDAC8 (34-36). Entinostat is a potent, orally available inhibitor of HDACs used in clinical practice for the treatment of refractory solid tumors and lymphoma $(37,38)$. Entinostat treatment has been reported to reverse the EMT phenotype (39) and to inhibit tumor-initiating cells in human TNBC cells (40). Therefore, the current study was designed with the aim of inhibiting VM by treatment with entinostat through the epigenetic re-expression of angiogenesis suppressor genes. Our data revealed that approximately $80 \%$ of TNBC cells with the stem cell phenotype potential formed VM structures in Matrigel. Treatment of the TNBC VM-forming cells with entinostat significantly suppressed the formation of VM structures. In addition, our data suggested that treatment of the TNBC VM-forming cells with entinostat led to the epigenetic re-expression of the anti-angiogenic genes, SERPINF1 and THBS2, and to that of the tumor suppressor genes, PTEN and p21. Entinostat also downregulated the expression of vascular endothelial growth factor A (VEGF-A), and of the EMT-related genes, Vimentin and $\beta$-catenin, in cells with the TNBC VM phenotype. Gene expression data analysis of breast cancer cohorts (METABRIC and TCGA) revealed that a high expression of the THBS2, SERPINF1, SERPINB5 and PTEN genes was associated with the overall survival (OS) of the patients. The findings of this study suggest that HDACs 1, 2, 3 partially contribute to TNBC VM formation that thus HDACs may be an important target for VM-dependent cancer therapy.

\section{Materials and methods}

Cells and cell culture. The human breast cancer cell lines, MDA-MB-231, BT-549 and MCF-7, were purchased from the American Type Culture Collection (ATCC, Manassas, VA, USA). LM2-4 is the lung metastatic version of MDA-MB-231 and was obtained from Dr John Ebos (Roswell Park Comprehensive Cancer Center, Buffalo, NY, USA). The MDA-MB-231 and LM2-4 were grown in Dulbecco's modified Eagle's medium (DMEM) supplemented with $10 \%$ fetal bovine serum (FBS) (both from Invitrogen/Thermo Fisher Scientific, Waltham, MA, USA). BT-549 cells were grown in RPMI medium (Gibco/Thermo Fisher Scientific) containing $10 \% \mathrm{FBS}$.

MCF-7 cells were grown in phenol red-free improved minimum essential medium (IMEM; Gibco/Thermo Fisher Scientific) supplemented with $0.25 \%$ glucose and $10 \%$ FBS. MCF10A human breast epithelial cell line was kindly provided by Dr S. Patnaik (Thoracic Surgery, Department of Surgical Oncology, Roswell Park Comprehensive Cancer Center, Buffalo, NY, USA). MCF10A cells were maintained in monolayer in Dulbecco's modified Eagle's medium-F12 (DMEM/F12) supplemented with 5\% horse serum (both from Invitrogen/Thermo Fisher Scientific), $0.5 \mu \mathrm{g} / \mathrm{ml}$ hydrocortisone, $100 \mathrm{ng} / \mathrm{ml}$ cholera toxin, $10 \mu \mathrm{g} / \mathrm{ml}$ insulin (all from Sigma-Aldrich), and $20 \mathrm{ng} / \mathrm{ml}$ recombinant human epidermal growth factor (EGF; PeproTech US, Rocky Hill, NJ). All the cell cultures were supplemented with $1 \%$ penicillin/streptomycin (Invitrogen/Thermo Fisher Scientific) and maintained at $37^{\circ} \mathrm{C}$ with $5 \% \mathrm{CO}_{2}$. The VM and sphere formation medium included DMEM/F12 supplemented with 1\% B27 (Gibco/Thermo Fisher Scientific), $10 \mathrm{ng} / \mathrm{ml}$ of fibroblast growth factor (FGF; PeproTech US) and $5 \mathrm{ng} / \mathrm{ml}$ of human EGF.

The identity of the cell lines was authenticated every 6 months by short tandem repeat (STR) (Roswell Park Comprehensive Cancer Center, Genomics Core). STR profiling aids in the detection of misidentified, cross-contaminated, or genetically drifted cells. To verify that cell lines are not false, misidentified, or are known to be authentic cell lines, we searched the Cellosaurus database (http://web.expasy.org/cellosaurus). Newly 
obtained cells were thawed, examined for expected morphology and for possible mycoplasma contamination, decontaminated if necessary, expanded ( $<3$ passages) and cryo-aliquoted for future studies. In the case that fresh starter stocks cannot be obtained, low-passage stocks were re-propagated to generate secondary low-passage aliquots. Every 6 months, cells were examined for mycoplasma contamination at the Roswell Park shRNA Core Facility by using the Agilent Mycoplasma Plus PCR Primer Set. The cultured cells were properly stored in liquid nitrogen and cell viability was examined before beginning the experiments. We always used low passage $(<10)$ cells in our experiments in order to obtain reproducible results.

Sphere formation assay. Sphere formation assay was carried out as previously described (41). Briefly, the cells were plated at a density of 20,000 cells/well in ultra-low attachment 24-well plates (cat. no. 29443-032; VWR, Radnor, PA, USA) in quadruplicate, and the experiment was performed several times. The cells were suspended in $40 \mu$ l DMEM F12 medium (Gibco/Thermo Fisher Scientific) and mixed thoroughly with $60 \mu \mathrm{l}$ BD Matrigel ${ }^{\mathrm{TM}}$ (cat. no. 354234BD; Biosciences, San Jose, CA, USA). The mixture was pipetted around the rim of the well, and the plate was incubated in a $5 \% \mathrm{CO}_{2}$ incubator at $37^{\circ} \mathrm{C}$ for $45 \mathrm{~min}$ to allow the BD Matrigel ${ }^{\mathrm{TM}}$ to solidify. A total of $500 \mu \mathrm{l}$ of DMEM F12 medium was added to each well and the plates were maintained in $5 \% \mathrm{CO}_{2}$ incubator at $37^{\circ} \mathrm{C}$ for 7 days. Vascular channels were quantified by counting the number of connected cells in 5 randomly selected fields at X10 magnification using a Nikon Ti-U inverted microscope (Nikon Instruments Inc., New York, NY, USA), and dividing the number by the total number of single cells in the same field. We also measured the VM tube length using ImageJ software version 1.52 (National Institutes of Health) and plotted as average tube length $(\mu \mathrm{m})$ per field.

Cytokine array. For cytokine array, the MDA-MB-231 cells were cultured under 2 different conditions. As a control treatment, the MDA-MB231 cells were grown in DMEM/F12 supplemented with B12, $10 \mathrm{ng} / \mathrm{ml}$ of FGF and $5 \mathrm{ng} / \mathrm{ml}$ of $\mathrm{EGF} / \mathrm{ml}$ without Matrigel plated in a low attachment 24-well plate for 7 days. The treatment condition was the same as that of the control, with the exception that the cells were grown on Matrigel. On day 7, medium was collected from each well and used for cytokine array using the human angiogenesis antibody array kit (\#ab193655; Abcam, Cambridge, MA, USA) following the manufacturer's instructions. In brief, the array membranes (membrane $\mathrm{C} 1$ ) were blocked with $10 \%$ blocking buffer for $20 \mathrm{~min}$. Subsequently, $1 \mathrm{ml}$ of medium from the control cells and treated cells was used to incubate the membranes overnight at $4^{\circ} \mathrm{C}$ followed by 3 washes with buffer I and 2 washes with buffer II. The membranes were then incubated with $1 \mathrm{X}$ biotinylated antibody cocktail followed by 1X HRP-conjugated streptavidin secondary antibody (both from Abcam) overnight at $4^{\circ} \mathrm{C}$. The following day, the membranes were washed with buffer I and buffer II. Membranes were developed using detection reagent on X-ray film.

Cytokine data analysis. Cytokine data analysis was carried following the instruction manual (Antibody array; Abcam). In brief, raw numeric densitometry data were extracted using densitometry software (AlphaEaseFC 4.0; Alpha Innotech, San Leandro, CA, USA). The background was subtracted and the data were normalized to the positive control signals for analysis. The following algorithm was used to calculate and determine the signal fold expression: $\mathrm{X}(\mathrm{NY})=\mathrm{X}(\mathrm{y}) \mathrm{x} 1 / \mathrm{P}(\mathrm{y})$, where $\mathrm{P} 1$ indicates the mean signal density of positive control spots on the reference array, $\mathrm{P}$ (y) indicates the signal density of positive control spots on the array treatment (VM condition), $\mathrm{X}(\mathrm{y})$ indicates the signal density for spot ' $\mathrm{X}$ ' on the array for sample ' $\mathrm{y}$ ' and $\mathrm{X}(\mathrm{NY})$ indicates the normalized signal intensity for spot ' $\mathrm{X}$ ' on array ' $\mathrm{y}$ '.

Immunofluorescence. The cells were fixed with $4 \%$ paraformaldehyde (PFA; Sigma-Aldrich)/Dulbecco's phosphate-buffered saline (DPBS; Thermo Fisher Scientific) for $20 \mathrm{~min}$ at room temperature, permeabilizedwith $0.2 \%$ Triton X-100/PBS for $5 \mathrm{~min}$ and then subjected to blocking in 10\% FBS/DPBS for $20 \mathrm{~min}$ at room temperature. For CD44 and CD34 staining, the cells were incubated with anti-CD44 (Clone DB105, \#130-113-334, 1:100 dilution) and anti-CD34 (Clone AC136, \#130-113-178, 1:100 dilution) FITC antibodies (Miltenyi Biotec Inc., Auburn, CA, USA) overnight at $4^{\circ} \mathrm{C}$, and washed 3 times in PBS. For hypoxia-inducible factor (HIF)-1 $\alpha$ (cat. no. 3716) and VEGFc (cat. no. 2445) (both from Cell Signaling Technology, Danvers, MA, USA) the cells were first stained with primary antibody (1:100 dilution, overnight at $\left.4^{\circ} \mathrm{C}\right)$ followed by washes 3 times with PBS and again incubated with Alexa Fluor 594-conjugated anti-rabbit secondary antibody (cat. no. A-11012; Thermo Fisher Scientific; 1:200 dilution, overnight at $4^{\circ} \mathrm{C}$ ).

Periodic Acid Schiff (PAS) staining. The cells were fixed at $4 \%$ PFA in PBS along with Matrigel for $20 \mathrm{~min}$ at room temperature, permeabilized with $0.2 \%$ Triton X-100 in PBS for $5 \mathrm{~min}$ and subjected to blocking with 5\% BSA in PBS for $20 \mathrm{~min}$ at room temperature. Vascular channels along with Matrigel were stained with PAS (Sigma-Aldrich) for $5 \mathrm{~min}$ followed by several washes with PBS at room temperature.

Flow cytometry. The cells were washed once with phosphate-buffered saline (PBS) and then harvested with $0.05 \%$ trypsin $/ 0.025 \%$ EDTA. The detached cells were washed with PBS containing $1 \%$ FBS and $1 \%$ penicillin/streptomycin (Thermo Fisher Scientific) and resuspended in the wash buffer at a concentration of $10^{6}$ cells in $100 \mu 1$. Combinations of fluorochrome-conjugated monoclonal antibodies obtained from BD Biosciences against human CD44 (fluorescein isothiocyanate; cat. no. 555478) and CD24 (phycoerythrin; cat. no. 555428) or their respective isotype controls were added to the cell suspension at concentrations recommended by the manufacturer and incubated at $4^{\circ} \mathrm{C}$ in the dark for 30-40 min. The cells were washed in wash buffer, resuspended in PBS, and analyzed on a Canto II flow cytometer (BD Biosciences).

Reverse transcription-quantitative polymerase chain reaction $(R T-q P C R)$. RT-PCR was performed to evaluate gene expression, as previously described (42). Briefly, the cells were dissolved in TRIzol reagent and total RNA was extracted using the isopropanol protocol (Invitrogen/Thermo Fisher Scientific). A total of $2 \mu \mathrm{g}$ of RNA (DNAse-treated) per sample was reverse 
transcribed using the cDNA synthesis kit (Invitrogen/Thermo Fisher Scientific). qPCR was carried using SYBR-Green human-specific primers (Invitrogen/Thermo Fisher Scientific). The following primers were used for RT-qPCR: Human cyclooxygenase (COX)-2 forward, 5'-CACAGCACAGCC AGGAAGG-3' and reverse, 5'-GTTCCCTGGCTCTGAGTA GTCGA-3'; human VEGF-A forward,5'-CTACCTCCACCATGC CAAGT-3' and reverse, 5'-GCAGTAGCTGCGCTGATAGA-3'; human aldehyde dehydrogenase 1 family, member A1 (ALDH1) forward, 5'-A ACTCCTCTCACTGCTCTCCACG-3' and reverse, 5'-GTCACCCTCTTCAGATTGCTTTTCC-3'; human p21 forward, 5'-TGTCCGTCAGAACCCATGC-3' and reverse, 5'-AAAGTCGAAGTTCCATCGCTC-3'; human PTEN forward, 5'-AGG GACGAACTGGTGTAATGA-3' and reverse, 5'-CTGGTCCTTACTTCCCCATAGAA-3'; human APC forward, 5'-CCTCATCCAGCTTTTACATGGC-3' and reverse, 5'-GCCCGAGCCTCTTTACTGC-3'; human SERPINF1 forward, 5'-GGAAATTCCCGATGAGATCAGC-3' and reverse, 5'-AGTCAAACTTTGTTACCCACTGC-3'; human THBS1 forward, 5'-TGCTATCACAACGGAGTTCAGT-3' and reverse, 5'-GCAGGACACCTTTTTGCAGATG-3'; human THBS2 forward, 5'-GCCCTCCTAAGACAAGGAACA-3' and reverse, 5'-CCACCCACGTTTCATTTTCCG-3'; human TIMP metallopeptidase inhibitor 3 (TIMP3) forward, 5'-CATGTG CAGTACATCCATA CGG-3' and reverse, 5'-CATCATAGA CGCGACCTGTCA-3'; human Vimentin forward, 5'-AGTCCA CTGAGTACCGGA GAC-3' and reverse, 5'-CATTTCACGCAT CTGGCGTTC-3'; human $\beta$-catenin forward, 5'-TCTGAGGAC AAGCCACAAGATTACA-3' and reverse, 5'-TGGGCACCA ATATCAAGTC CAA-3'; human CD44 forward, 5'-AGAAGG TGTGGGCAGAA GAA-3' and reverse, 5'-AAATGCACC ATTTCCTGAGA-3'; human AlkB homologue 5 (ALKBH5) forward, 5'-AGTTCCAGTTCAAGCCTATTCG-3' and human ALKBH5 reverse, 5'-TGAGCACAGTCACGCTTCC-3'; human HDAC1 forward, 5'-CCGCATGACTCATAATTTGCTG-3' and reverse, 5'-ATTGGCTTTGTGAGGGCGATA-3'; human HDAC2 forward, 5'-ATGGCGTACAGTCAAGGAGG-3' and reverse, 5'-TGCGGATTCTATGAGGCTTCA-3'; human HDAC3 forward, 5'-GCAAGGCTTCACCAAGAGTCT-3' and reverse, 5'-AGATGCGCCTGTGTAACGC-3'; and human GAPDH forward, 5'-CTTAGCACCCCTGGCCAAG-3 and reverse, 5'-GATGTTCTGGAGAGCCCCG-3'. Each qPCR sample was run in triplicate. Gene expression levels were calculated by $2^{-\triangle \Delta C q}$ method (43) and normalized to GAPDH or $\beta$-actin expression.

Western blot analysis. Western blot analysis was performed as previously described (42). Briefly, cells were lysed by probe-sonication in lysis buffer A $[20 \mathrm{mM}$ Tris $(\mathrm{pH} \mathrm{7.4),}$ $20 \%$ glycerol, $400 \mathrm{mM} \mathrm{NaCl}, 0.5 \%$ NP-40, 20\% glycerol, $5 \mathrm{mM}$ sodium orthovanadate, $40 \mathrm{mM} \beta$-glycerophosphate, $15 \mathrm{mM} \mathrm{NaF}, 0.5 \mathrm{mM}$ 4-deoxypyridoxine, and protease inhibitor cocktail (Sigma-Aldrich)]. Cell lysates were diluted in the buffer B (lysis buffer A without $\mathrm{NaCl}$ ) to make final $\mathrm{NaCl}$ concentration approximately 100-150 mM. Unbroken cells were removed by centrifugation at $700 \mathrm{x}$ g for $10 \mathrm{~min}$ at $4^{\circ} \mathrm{C}$. Protein concentrations were measured by Bradford method (Bio-Rad, Hercules, CA, USA). A total of $20 \mu \mathrm{g}$ of protein loaded per lane and separated by $10 \%$ SDS-PAGE and transferred to nitrocellulose membranes. Membranes were blocked with $5 \%$ blocking solution in $1 \mathrm{X}$ TBST buffer (both from Bio-Rad) at room temperature for $1 \mathrm{~h}$. Membranes were incubated overnight at $4^{\circ} \mathrm{C}$ with the primary antibodies (1:1,000 dilution) in TBST buffer (Bio-Rad). Membranes were washed thoroughly with TBST buffer at room temperature and followed by incubation ( $1 \mathrm{~h}$ at room temperature) with the rabbit or mouse secondary antibodies (1:5,000 in TBST with $1 \%$ blocking solution). Membranes were washed thoroughly at room temperature and developed with the enhanced chemiluminescence (ECL) western blotting substrate (\#32106; Pierce/Thermo Fisher Scientific). Image the membranes by exposing to X-ray films (Kodak).

The following primary antibodies were used for western blot analysis: phospho-p44/42 MAPK (ERK1/2) (Thr202/Tyr204) (\#4370), phospho-AKT (Ser473) (\#4060), phospho-p38 MAPK (Thr180/Tyr182) (\#4511), phospho-STAT3 (Tyr705) (\#4113), HDAC1 (\#34589), HDAC2 (\#57156), HDAC3 (\#85057), acetyl-histone H3 (Lys9) (\#9649), H3-total (\#4499), p21 Waf1/Cip1 (\#2947) and lamin A/C (\#2032) (all antibodies purchased from Cell Signaling Technology), and Clathrin HC (\#sc-12734) (Santa Cruz Biotechnology, Santa Cruz, CA, USA). The following secondary antibodies were used for western blot analysis: peroxidase-conjugated affipure goat anti-rabbit IgG (\#111-035-045) and goat anti-mouse IgG (\#115-035-062) (both from Jackson ImmunoResearch Laboratories, Inc., West Grove, PA, USA).

Staining of live/dead cells. Live-dead assays were performed in ultra-low attachment 48 -well plates as previously described (44). Briefly, VM-forming cells were treated with entinostat (1 $\mu \mathrm{M})$ (\#13284; Cayman Chemical Co., Ann Arbor, MI, USA) for 48-96 h and cells were simultaneously stained with green-fluorescent calcein-AM as a measure of intracellular esterase activity of living cells and red-fluorescent ethidium homodimer-1 to determine dead cells by the loss of plasma membrane integrity (LIVE/DEAD Viability/Cytotoxicity kit; L3224; Life Technologies/Thermo Fisher Scientific). Cells were visualized at $\times 10-x 20$ magnification using a Nikon Ti-U inverted fluorescence microscope (Nikon Instruments Inc., New York, USA) and viable (green) and dead cells (red) were shown.

Breast cancer OS data analysis. The Cancer Genome Atlas (TCGA) breast cancer (BRCA) cohort of 1,092 patients was used to investigate the association between the Kaplan-Meier analyses of overall survival (OS) difference of the patients and the expression levels of genes of interest. The log-rank cutoff of gene expression distribution is median of the gene level. TNBC and non-TNBC group of patients were classified by using PAM50 gene expression levels. OS difference of expression of genes in the sub-group of patients and in the whole cohort were analyzed. For each gene, patients were dichotomized into low and high expression groups based on the gene expression. The dichotomization was defined using a running Cox proportional hazard statistics (45). Differences in the OS between the 2 groups were assessed at multiple candidate cut-off points, and the optimal cut-off point was selected based on the statistical significance of the model. Molecular Taxonomy of Breast Cancer International Consortium (METABRIC) was also used to evaluate a cohort 
of 1,904 patients with breast cancer. A similar statistical analysis was performed for the METABRIC data.

The expression levels of genes of interest were compared between normal and tumor samples in the TCGA dataset. The Mann-Whitney U test was used to determine whether there was a significant difference in gene expression between the normal and tumor samples. The subpopulation for tumor samples (TNBC) was investigated using the same method, with normal samples as pooled samples from the whole cohort.

Statistical analysis. Statistical analysis was performed using an unpaired two-tailed Student's t-test for the comparisons of 2 groups (using GraphPad Prism version 7.0a). The levels of mRNAs and cytokine array signal intensity (fold) are expressed as the means \pm SD or means \pm SEM. We used one-way ANOVA test for datasets containing multiple group comparisons and Tukey's post-hoc test for the family-wise error rate comparison. All experiments were repeated independently at least three times and representative data are shown. For all analyses, $\mathrm{P} \leq 0.05$ was considered statistically significant.

\section{Results}

Intrinsic properties of invasive TNBC cells which are able to generate VM when mixed with Matrigel. Tumor cell activity in Matrigel is representative of tumor pathology and the basement membrane matrix mimics the microenvironment of tumor cells in vivo and affects morphology and molecular responses (46). The morphology of cancer cells reflects their malignant and invasive potential. VM refers to the process through which aggressive cancer cells have the intrinsic property to transdifferentiate and mimic the endothelial phenotype to form vessel-like structures. The cancer stem cell phenotype is associated with aggressiveness and invasive potential $(4,47)$. In this study, to understand the intrinsic differential cancer phenotype, we examined TNBC and estrogen receptor (ER)-positive cell lines for tube formation assay. In our experiment, we used highly aggressive metastatic human TNBC MDA-MB-231 cells, and the LM2-4 cell line, which is lung metastatic version of the MDA-MB-231 cell line (42), and luminal-type non-aggressive breast cancer MCF-7 cells to form a net-like tubular vessel-like structure. It has been well established that Matrigel enhances the aggressive behavior of cancer cells, promoting them to form VM formations which mimic the basement membrane in vivo (48). In this study, we observed that cells embedded within Matrigel exhibited two differential morphologies, which is closer to the physiologically relevant model. The sphere formation assay data revealed that the MDA-MB-231 (Fig. 1A) and LM2-4 cells (Fig. 1B) formed both tumorspheres and net-like structures when mixed with Matrigel and were seeded in low attachment plates at day 7. All cells formed only tumorspheres when they were seeded in low attachment plates without Matrigel (data not shown). By contrast, the MCF-7 cells formed tumorspheres only and failed to form a network structure under Matrigel culture conditions (Fig. 1C). As we observed that both the MDA-MB-231 and LM2-4 cells exhibited two different morphologies (tumorspheres and vascular network) when mixed with Matrigel seeded in low attachment plates, we calculated the percentage of MDA-MB-231 cells joined together to form a net-like structure versus tumorspheres in 3 independent fields. The data revealed that approximately $80 \%$ of the cells joined together to form a net-like structure, while $20 \%$ of the cells formed tumorspheres under the same conditions following $96 \mathrm{~h}$ of culture (Fig. 1D) by virtue of their high plasticity $(49,50)$. Since cancer stem cell (CSC) marker CD44 expression facilitates the formation of vasculogenic structures in vitro, and as CD44 knockdown suppresses migration and vascular network formation (50), in this study, we then used FACS analysis to identify the proportion of $\mathrm{CD} 44^{+} / \mathrm{CD} 24$ CSCs in the metastatic TNBC cells. In agreement with the findings of previous studies $(51,52)$, our data revealed that $>90 \%$ of the LM2-4 cell populations comprised CD $44^{+} / \mathrm{CD} 24$ cells (Fig. 1F) compared to the MCF-7 cells which had a CD $24^{+}$population of approximately $99 \%$ (data not shown). On day 7, we stained the MDA-MB-231 cells with the PAS to highlight matrix-associated vascular channels. The staining data indicated that the vascular channels were stained positive for PAS, confirming that the cells secreted glycogen and mucopolysaccharides to form ECM-rich channels (Fig. 1E). Overall, these data demonstrate that the TNBC cells have the intrinsic properties of forming VM structures when mixed with Matrigel in a 3D preclinical model.

VM structures formed by TNBC cells express both vascular endothelial and stem cell marker genes. Previous studies have reported that MDA-MB-231 cells express CD34, an endothelial progenitor marker (53) when grown on Matrigel that had undergone VM (54). CD44, a marker of EMT, has been shown to enhance tumor aggressiveness by promoting cell plasticity (50). In this study, we examined CD44 and CD34 expression levels using fluorescently tagged antibodies in the MDA-MB-231 cells grown in a 3D Matrigel matrix environment. Intriguingly, the data revealed that the tube-forming cells, but not the tumorsphere-forming cells were CD44-positive (Fig. 2A), while both groups of cells stained positive for VEGFc, HIF-1 $\alpha$ and CD34 as shown in Fig. 2B-D. These data indicate that despite the same environmental conditions, $80 \%$ of the cells have the intrinsic capability to express stem cell properties and are more aggressive.

Vascular mimicry is associated with the angiogenic pathway in TNBC cells, as determined by gene expression analysis $(55,56)$. In this study, we then further investigated the angiogenesis-related cytokines that are secreted into the media during VM formation compared with the control cells seeded under normal cell culture conditions. The data revealed that the levels of major angiogenic proteins were significantly upregulated by VM formation and these were VEGF, angiogenin (ANG), interleukin (IL)8, TIMP1 and TIMP2 (Fig. 2E-H). In addition, the levels of two important mediators, interferon (IFN) $\gamma$ and monocyte chemoattractant protein-1 (MCP-1/CCL2), known to influence tumor growth in the tumor microenvironment, were found to be significantly elevated during the VM formation of the TNBC cells compared to the cells grown under normal conditions (Fig. 2E-H). Notably, we found that TGF- $\beta$ expression was downregulated during VM formation (Fig. 2E-H). Previous reports have indicated that the inhibition of TGF- $\beta$ signaling increases VEGF-A expression and angiogenesis, which can contribute to the enhancement of the metastasis of cancer cells $(57,58)$. 
A

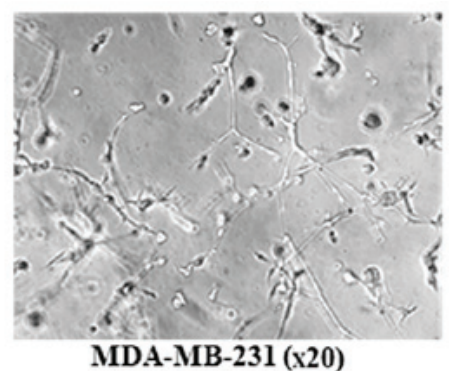

D

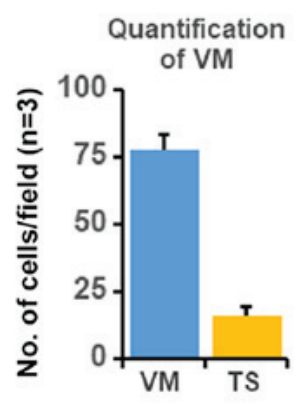

MDA-MB-231

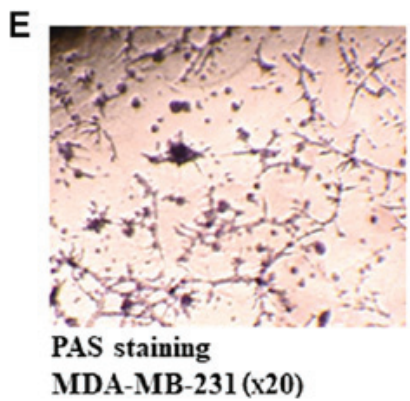

F
B

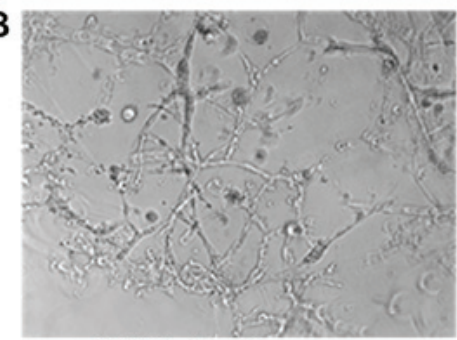

LM-2-4 (x20)

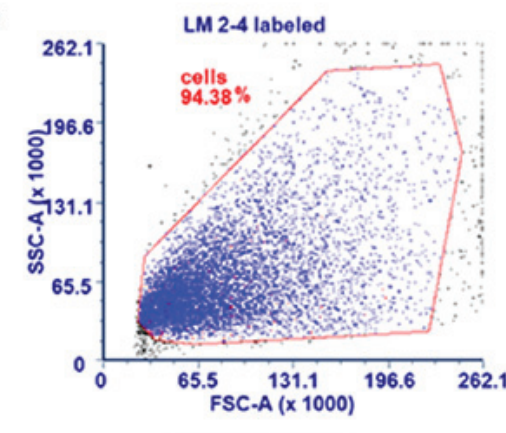

LM 2-4 unstained

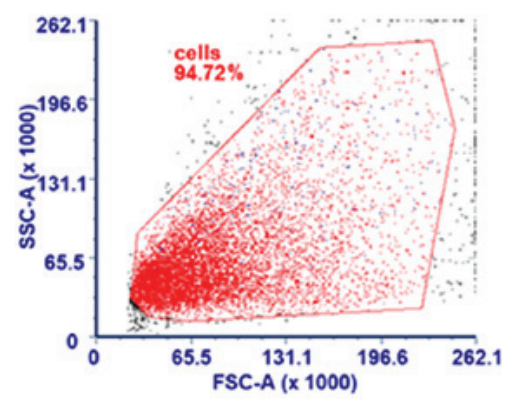

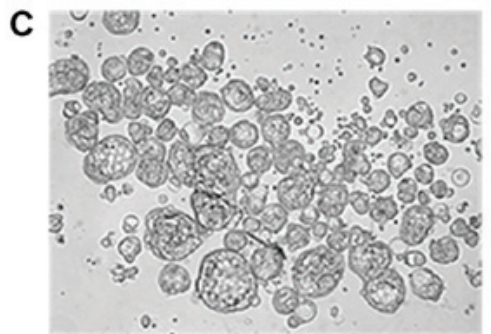

MCF-7 (x20)

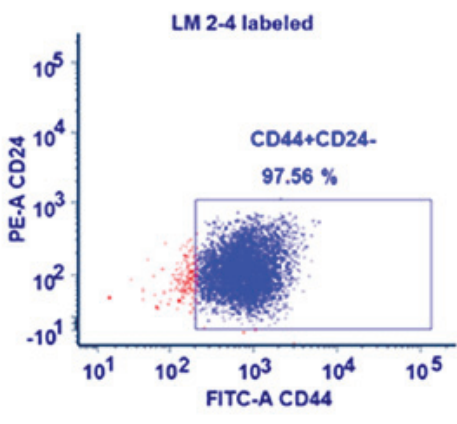

LM 2-4 unstained

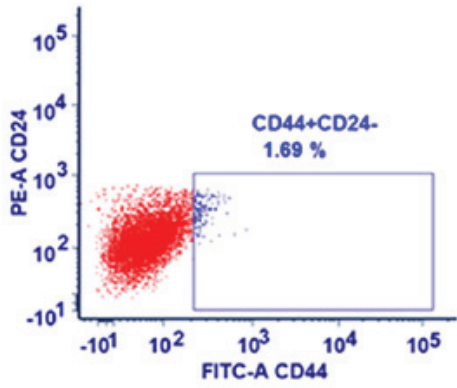

Figure 1. TNBC cells form the vascular channel in a 3D preclinical cell culture model. In total, 10,000 cells of each cell line of (A) MDA-MB-231 cells, (B) LM2-4 cells and (C) MCF-7 cells were plated in low attachment tissue culture plates mixed with growth factor reduced Matrigel for 7 days to obtain vascular channel formation. The experiments were repeated 3 times and representative phase contrast images (x20 magnification) of vascular channel are shown for each cell line. MDA-MB-231 and LM-2-4 cells formed well-defined tubular structures along with spheroids compared with the MCF-7 cells, which formed only spheroids. (D) Vascular channels and spheroids of MDA-MB-231 cells were counted in three independent fields and plotted. (E) Periodic acid-Schiff (PAS)-positive substances formed a basement membrane-like structure. Representative VM channels are lined with tumor cells and rich in PAS $^{+}$substances. The experiments were repeated 3 times and representative images of PAS staining of MDA-MB-231 are shown. (F) Identification of a CD44/CD24 subpopulation in TNBC LM2-4 cells by flow cytometry. LM2-4 cells exhibited a 97.56\% CD44 /CD24 antigen phenotype.

Entinostat treatment inhibits VM formation in TNBC cells. A number of correlative studies have shown the aberrant expression of HDACs in cancer regulate cell cycle progression, proliferation and develop cancer (59-62). Class I HDACs 1,2 and 3 are overexpressed in breast cancer and are associated with a more aggressive tumor type (60). HDACs induce angiogenesis via the negative regulation of tumor suppressor genes (63). HDAC3 signaling mechanisms have been shown to be involved in VM formation (64). Epigenetic mechanisms mediate the suppression of tumor suppressors or anti-angiogenesis marker genes and are hallmarks of VM formation and cancer progression. Thus, in this study, we examine whether the re-expression of these genes by treatment with entinostat (MS-275), a selective inhibitor of class I HDACs, can abolish VM structures in a 3D Matrigel cell culture. Since entinostat is a well-tolerated HDAC inhibitor that has exhibited promising therapeutic potential in both solid and hematologic malignancies (65), we first wished to examine whether it reduces VM structures in TNBC cells. Entinostat alone or in its combination with doxorubicin, a cytotoxic compound used in TNBC treatment, has been shown to induce tumor regression in $\operatorname{TNBC}(40,66)$. On the other hand, the pan HDAC inhibitor, vorinostat (SAHA), at an $\mathrm{IC}_{50}$ of $5.1 \mu \mathrm{M}$ has been shown to reduce the growth of TNBC MDAC-MB-231 cells (67). In agreement with previously published results that SAHA suppresses VM and the proliferation of highly aggressive pancreatic cancer PaTu8988 cells (68), the data of this study suggested that at a suboptimal dose ( $2 \mu \mathrm{M}$ for $24 \mathrm{~h})$ it also reduces VM structures and enhances the apoptosis of MDA-MB-231 and BT-549 TNBC cells (data not shown). From one of the class I HDACs, HDAC 3 has been linked with the VM phenotype of cancer cells. Thus, we decided to use entinostat to examine whether it can reduce the VM phenotype in various TNBC cells. Since the $1 \mu \mathrm{M}$ dose of Entinostat $(72 \mathrm{~h}$ treatment) has been shown to reduce the $\mathrm{CD} 44^{\text {high }} / \mathrm{CD} 24^{\text {low }}$ cell population and markers of tumor-initiating cells (TIC) in TNBC cells (40), we used 1 and $0.5 \mu \mathrm{M}$ or even lower doses of this drug to examine the effect on VM structures in various 


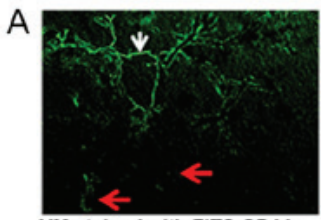
VM stained with FITC.CD44 antibody $(\times 20)$

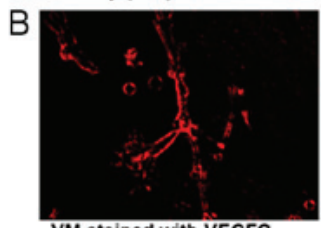
VM stained with VEGFC antibody $(\times 20)$

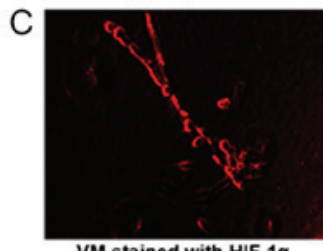
VM stained with HIF-1a antibody (x20)

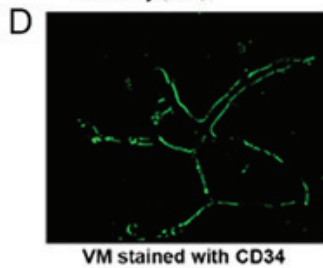

VM stained with CD34 antibody (x20)

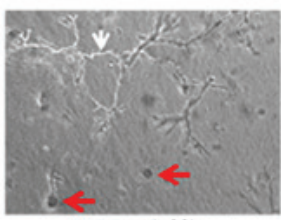

VM DIC ( $\times 20)$

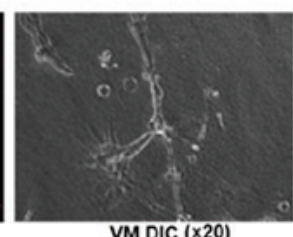

VM DIC (x20)
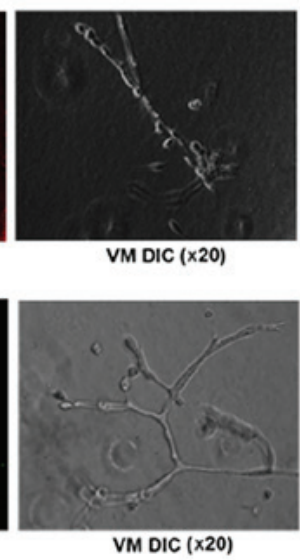

E

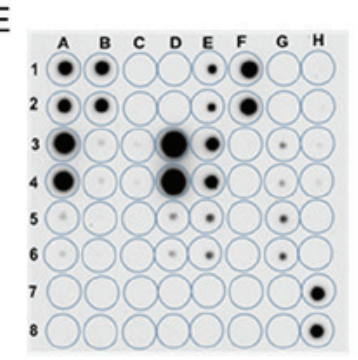

$\mathrm{F}$

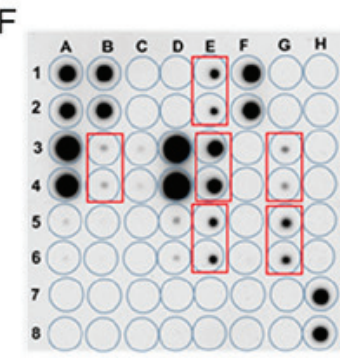

G

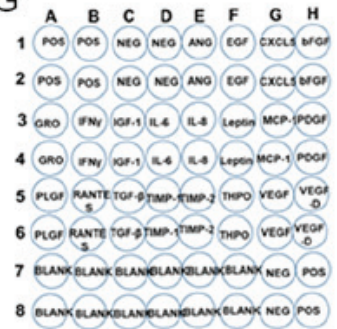

$\mathrm{H}$

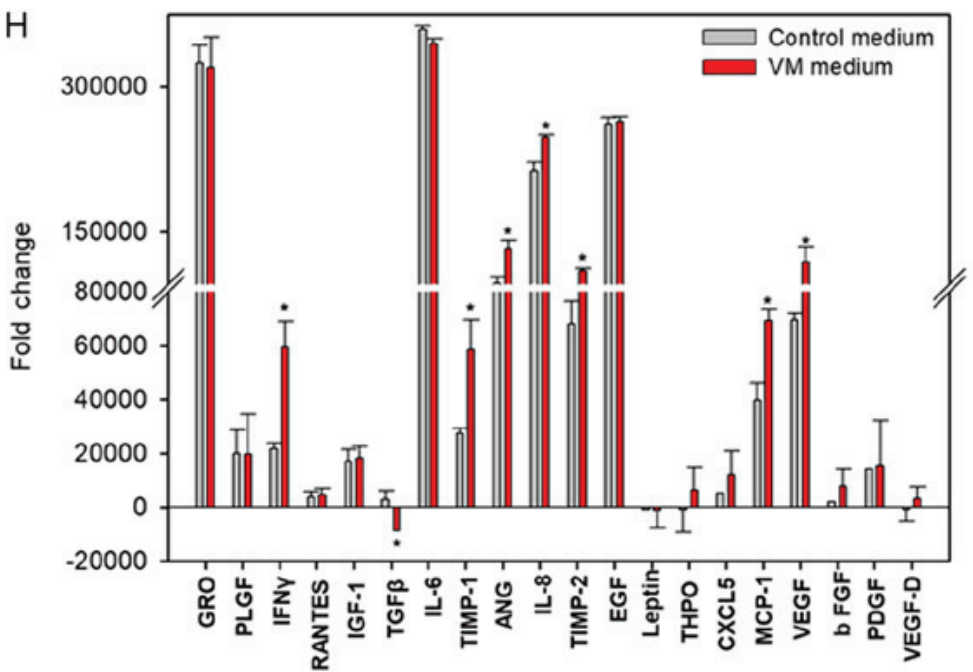

Figure 2. VM formed by TNBC cells expresses vascular endothelial- and stem cell marker-related genes. Vascular channels of MDA-MB-231 cells in Matrigel were fixed with paraformaldehyde and stained with (A) anti-CD44-FITC antibody, (B) anti-VEGFc antibody, (C) anti-HIF-1 $\alpha$ antibody, and (D) anti-CD34 antibody. Alexa Fluor 594 conjugated secondary antibody (B and C) and FITC secondary antibody (D) were used. Fluorescence images (x20 magnification) were captured and corresponding phase contrast images are shown. The experiments were repeated 3 times and representative images are shown. (E-H) Human Angiogenesis Antibody Array: VM cell supernatant analysis of angiogenesis proteins revealed increased levels compared to non-VM cell culture supernatant. (F) VM supernatant on day 7 isolated from MDA-MB-231 cells along with the matching cell culture supernatant of (E) MDA-MB-231 cells were tested on a human angiogenesis protein array. Higher amount of proteins (VEGF, ANG, IL-8, TIMP1, TIMP2, MCP-1 and IFN- $\gamma$ ) based on gray levels or brightness values in VM supernatants (red boxes) as compared with control in (E). The array template is shown in the right panel (G). (H) Quantification of protein expression data, shown as fold change. TNBC, triple-negative breast cancer; VM, vasculogenic mimicry; GRO, growth regulated oncogene; ANG, Angiopoietin; bFGF, basic fibroblast growth factor; EGF, epidermal growth factor; PLGF, placenta growth factor; IFN, interferon; IGF, insulin-like growth factor; IL, interleukin; MCP, monocyte chemoattractant protein; PDGF, platelet-derived growth factor; TGF, transforming growth factor; ENA-78 (CXCL5), epithelial-neutrophil activating peptide; RANTES, regulated on activation, normal T cell expressed and secreted; TIMP, tissue inhibitor of matrix metalloproteinase; VEGF, vascular endothelial growth factor. Cytokines array signal intensities (fold) were plotted (means $\pm \mathrm{SD}$ ), ${ }^{*} \mathrm{P}<0.05$ vs. control.

TNBC cells in this study. As expected, the TNBC cells had a higher expression of HDACs 1, 2, 3 expression compared to the benign breast tumor MCF10A cells (Fig. 3A and B). The data revealed that entinostat treatment $(10-500 \mathrm{nM})$ for 3 days in 3D Matrigel cell culture markedly reduced the VM structures (average tube length) in the TNBC BT-549 (Fig. 3C), LM2-4 (Fig. 3D) and MDA-MB-231 (Fig. 3E) cells. Entinostat has been shown to exert inhibitory effects on cell proliferation and to promote apoptosis in breast cancer (69). In this study, we found that treatment of the TNBC cells with entinostat $(0.5 \mu \mathrm{M})$ enhanced the amount of dead cells in the 3D Matrigel cell culture model (BT-549, Fig. 3F and G; data not shown for the MDA-MB-231 and LM2-4 cells). Taken together, these data suggest that class I HDACs are important for the VM phenotype in TNBC cells and that entinostat reduces the VM phenotype and enhances cell death in various TNBC cells.

Entinostat treatment alters the expression levels of tumor suppressor and anti-angiogenesis-related genes. Before the discovery of $\mathrm{VM}$, researchers attempated to use anti-angiogenesis therapy as an alternative to control tumor growth. However, it was recently reported that anti-angiogenesis therapy was not effective or worse, it may elicit further malignancy in TNBC via the formation of VM structures (21). In this study, although entinostat treatment did not exert a predominant effect on the phosphorylation of AKT, ERK, p38, STAT3 in our experimental setting, as expected, it enhanced chromatin histone acetylation in TNBC cells (Fig. 4A) that is linked to epigenetic gene regulation. We thus wished to determine whether the epigenetic re-activation of anti-angiogenesis-related genes by treatment with entinostat would exert more prominent therapeutic effects. Our data revealed that treatment with entinostat increased the expression of the anti-angiogenesis-related genes, THBS2, SERPINF1 and SERPINB5 (70) (Fig. 4E-G). However, the data suggested that the expression levels of the inhibitors of angiogenesis genes, TIMP1 $(71,72)$ and THBS1 $(73)$, were markedly reduced by treatment of these VM-forming cells with entinostat (Fig. 4H and I). For the first time, at least to the best of our knowledge, we report that the treatment of TNBC cells with 
A
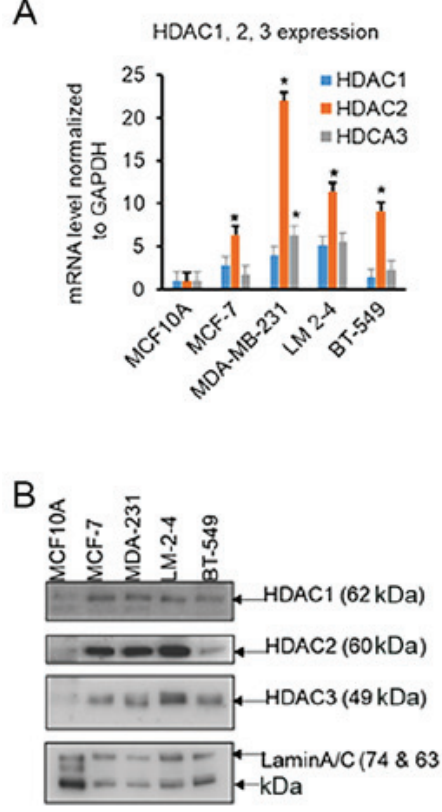
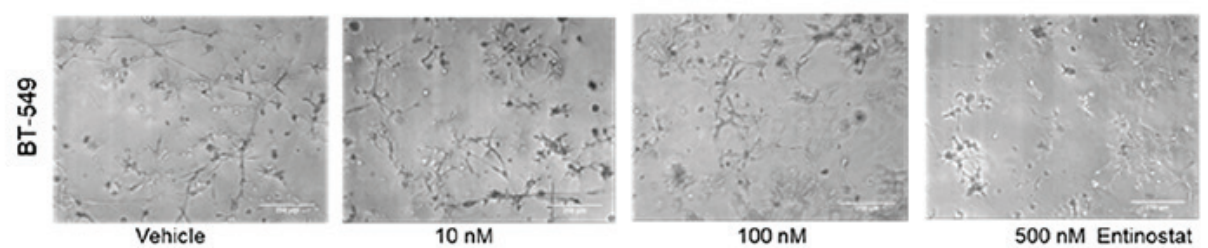

C

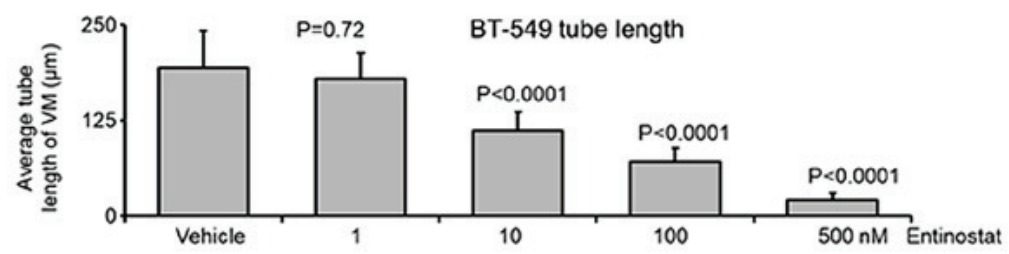

D
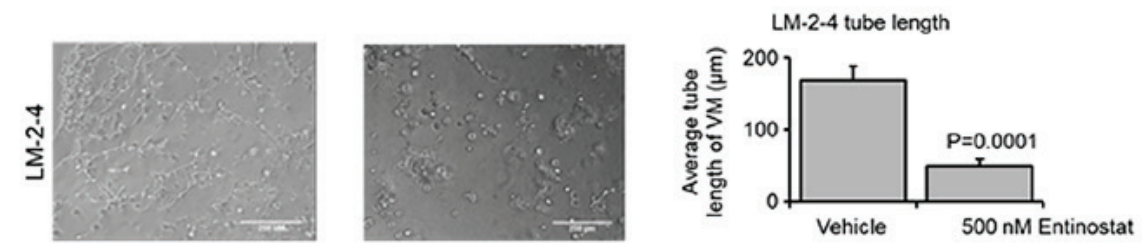

E
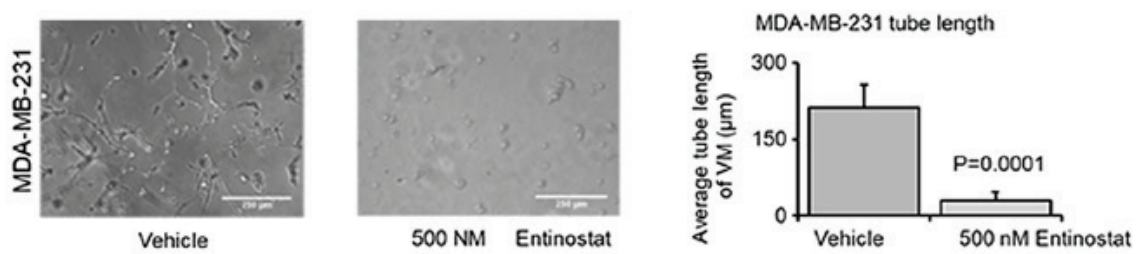

F
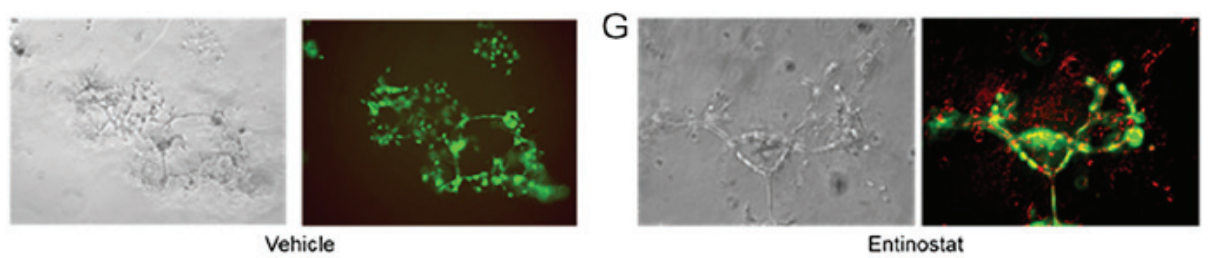

Figure 3. Entinostat reduces VM structures in TNBC cells. RNAs were extracted from the human breast tumor benign MCF10A, ER ${ }^{+}$MCF-7, and TNBC MDA-MB-231, LM2-4 and BT-549 cells. (A) SYBR-Green qPCR analysis was performed for the human HDACs 1, 2, 3 genes. Gene levels were examined by the $\Delta \Delta \mathrm{Cq}$ method and normalized to the housekeeping gene, GAPDH (means $\pm \mathrm{SD}$ ). The overall two-way ANOVA P-value for this dataset is $<0.0001$. Tukey's post-hoc test that corrects for family-wise error rate was conducted for comparing each group to the MCF10A group for HDAC1, HDAC2 and HDAC3 normalized mRNA expression levels. (B) Protein extracts from the cells (A) were used for western blot analysis with the indicated antibodies. Blots were stripped and re-probed with anti-Lamin A/C to show equal loading and transfer. Similar results were obtained in three additional experiments. VM formed by TNBC cells were treated with entinostat [1 to $500 \mathrm{nM}$ for BT-549 cells (C); $500 \mathrm{nM}$ for LM2-4 and MDA-MB-231 cells (D and E, respectively)], at day 3 of cell plating for $72 \mathrm{~h}$ in full serum. Phase-contrast images were captured and are shown (x10 magnification, C and E). VM tube lengths were measured from 4 separate fields using ImageJ software and the average tube length was plotted (means \pm SD) (C-E). The overall P-value (ANOVA) for the dataset is $<0.0001$ Tukey's post-hoc test that corrects for family-wise error rate is conducted for comparing each group to the control group, and the P-values are shown (C). The P-value (Student's t-test) for the data set (entinostat vs. vehicle) is 0.0001 (D and E). Live and dead BT-549 cells were in green and red in live/dead cells staining. (F) Live cells (green) were observed in VM of BT-549 cells (vehicle group). (G) VM structures were abolished and red spots (dead cells) were increased after $72 \mathrm{~h}$ of entinostat treatment $(0.5 \mu \mathrm{M})$ at day 5 of cell plating. Similar results were obtained for the LM2-4 and MDa-MB-231 cells (data not shown). Experiments were repeated 3 times and representative images are shown. TNBC, triple-negative breast cancer; VM, vasculogenic mimicry.

the VM phenotype with class I HADC inhibitor leads to the re-expression of important anti-angiogenesis-related genes. PTEN seems to be an important tumor suppressor gene reported to be epigenetically silenced in cancers $(32,74)$. CDKN1A (p21WAF1/CIP1) is a CDK inhibitor that is induced by HDAC inhibitors by promoter histone acetylation (75). Our data also revealed that treatment of the VM-forming cells with entinostat markedly upregulated the expression of the tumor suppressor genes, p21, PTEN and APC (76) (Fig. 4B-D). However, no significant difference was observed in the expression levels of p21, PTEN, THBS2 and SERPINEF1 between the control cells grown in normal tissue culture plates compared with the cells that formed VM on Matrigel (Fig. 4B, C, E and F).
Entinostat treatment reduces the expression of angiogenesis-related genes. To further investigate whether entinostat affects the expression of angiogenesis-related genes, we performed RT-qPCR to examine the transcript levels of VEGF-A, Vimentin and $\beta$-catenin. Since VM formation enhanced the expression of angiogenesis-related genes compared to the control cells (Fig. 5A-C), we wished to examine whether entinostat affects these genes. The data revealed that the levels of VEGF-A, Vimentin and $\beta$-catenin were significantly downregulated following treatment of the VM-forming cells with entinostat compared to the control cells (Fig. 5A-C). The mechanisms through which HDAC inhibitors reduce the expression of the angiogenesis-related 

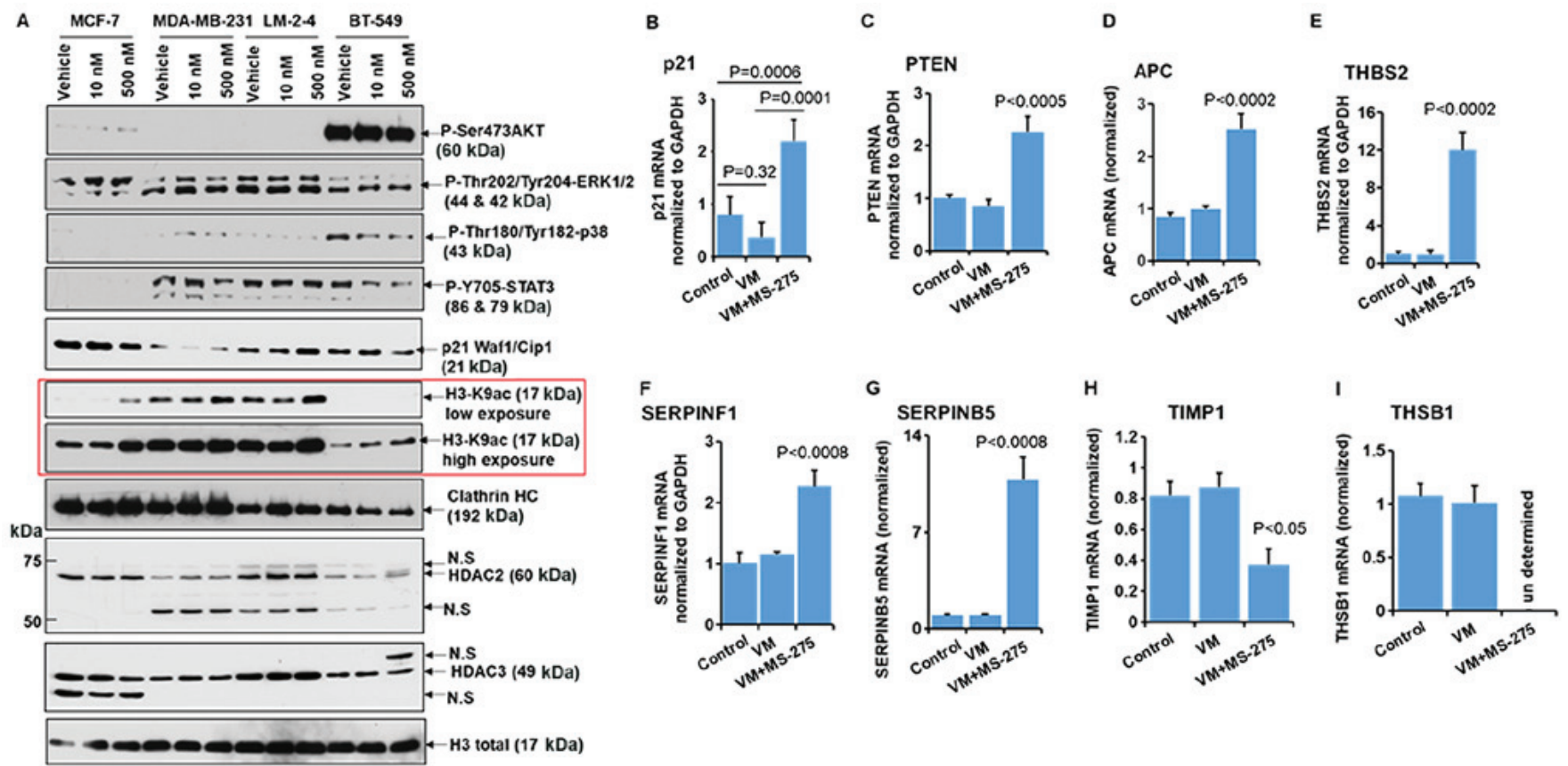

Figure 4. Entinostat enhances the expression of tumor suppressor genes and anti-VM genes in TNBC VM-forming cells. (A) Cells were treated with entinostat for $72 \mathrm{~h}$ as indicated. Total protein extracts from the MCF10A, MCF-7, MDA-MB-231, LM2-4 and BT-549 cells were used for western blot analysis with the indicated antibodies. Histone $\mathrm{H} 3$ and Clathrin $\mathrm{HC}$ antibodies were used to show equal loading. Similar results were obtained in 3 additional experiments. Representative blots are shown. N.S indicates the non-specific band. (B-I) Gene expression analysis. VM was formed in a low attachment plate with Matrigel from MDA-MB-231 cells. After 6 days of plating of the cells, VM was treated with entinostat $(1 \mu \mathrm{M})$ for 3 days and RNAs were extracted using TRIzol reagent. SYBR-Green qPCR analysis was performed for the indicated genes: (B) p21, (C) PTEN, (D) APC, (E) THBS2, (F) SERPINF1, (G) SERPINB5, (H) TIMP1, and (I) THBS1. Gene expression levels were calculated by the $\Delta \Delta \mathrm{Cq}$ method and normalized to GAPDH expression. Data are the means $\pm \mathrm{SD}(\mathrm{n}=3)$. The ANOVA P-value for each gene is $<0.005$ and Tukey's post-hoc P-values for pairwise comparison are shown (B-I). TNBC, triple-negative breast cancer; VM, vasculogenic mimicry.

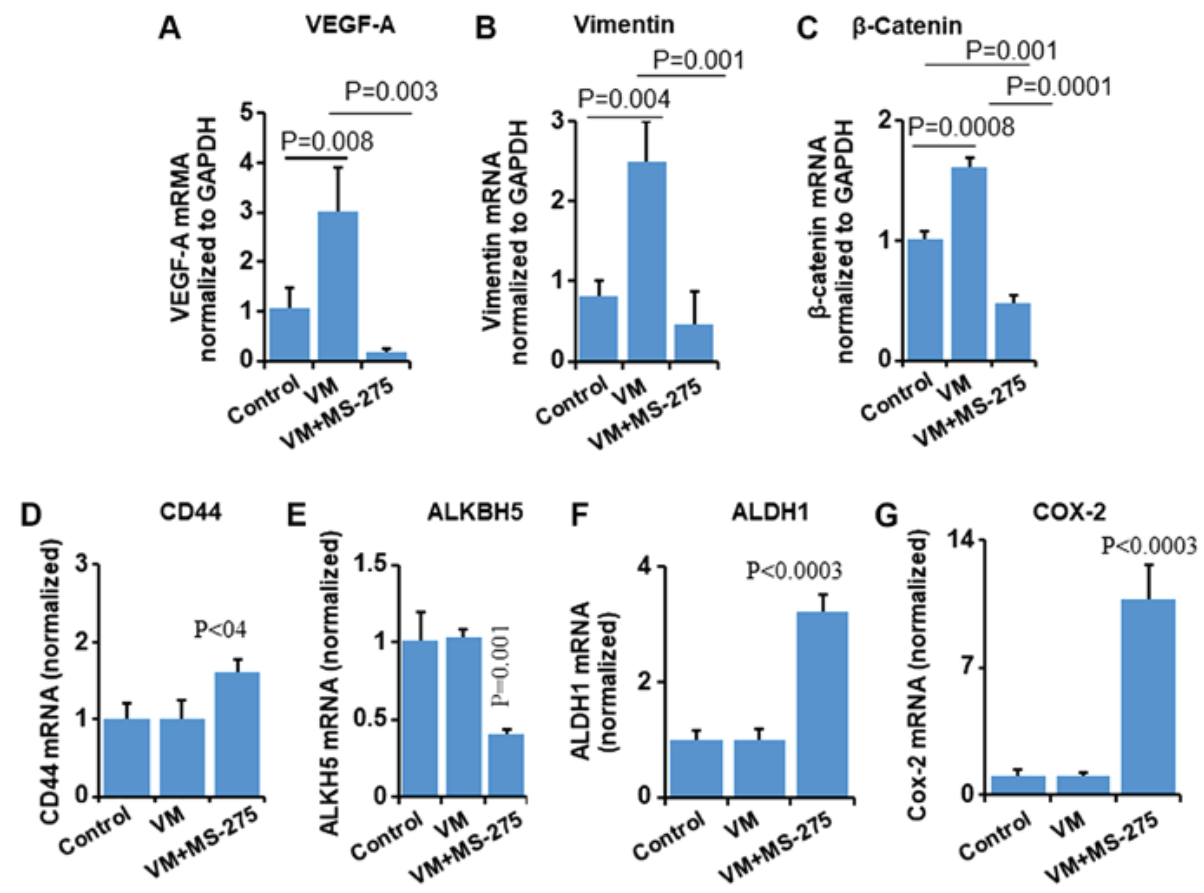

Figure 5. Entinostat reduces the levels of pro-VM genes in TNBC VM-forming cells. VM was formed in a low attachment plate with Matrigel. After 6 days of plating of the cells, VM was treated with entinostat $(1 \mu \mathrm{M})$ for 3 days and RNAs were extracted using TRIzol reagent. SYBR-Green qPCR analysis was performed for the indicated genes: (A) VEGFA, (B) Vimentin, (C) $\beta$-catenin, (D) CD44, (E) ALKBH5, (F) ALDH1, and (G) COX-2. Gene expression levels were calculated by the $\Delta \Delta \mathrm{Cq}$ method and normalized to GAPDH expression. Data are the means $\pm \mathrm{SD}, \mathrm{n}=3$. The ANOVA P-value for each the gene is $<0.03$ and Tukey's post-hoc P-values are shown (A-G). TNBC, triple-negative breast cancer; VM, vasculogenic mimicry.

genes are not yet well understood and they may involve an indirect effect. However, it has been reported that HDAC inhibitors regulate gene expression through histone and transcription factor hyperacetylation, which correlates with 

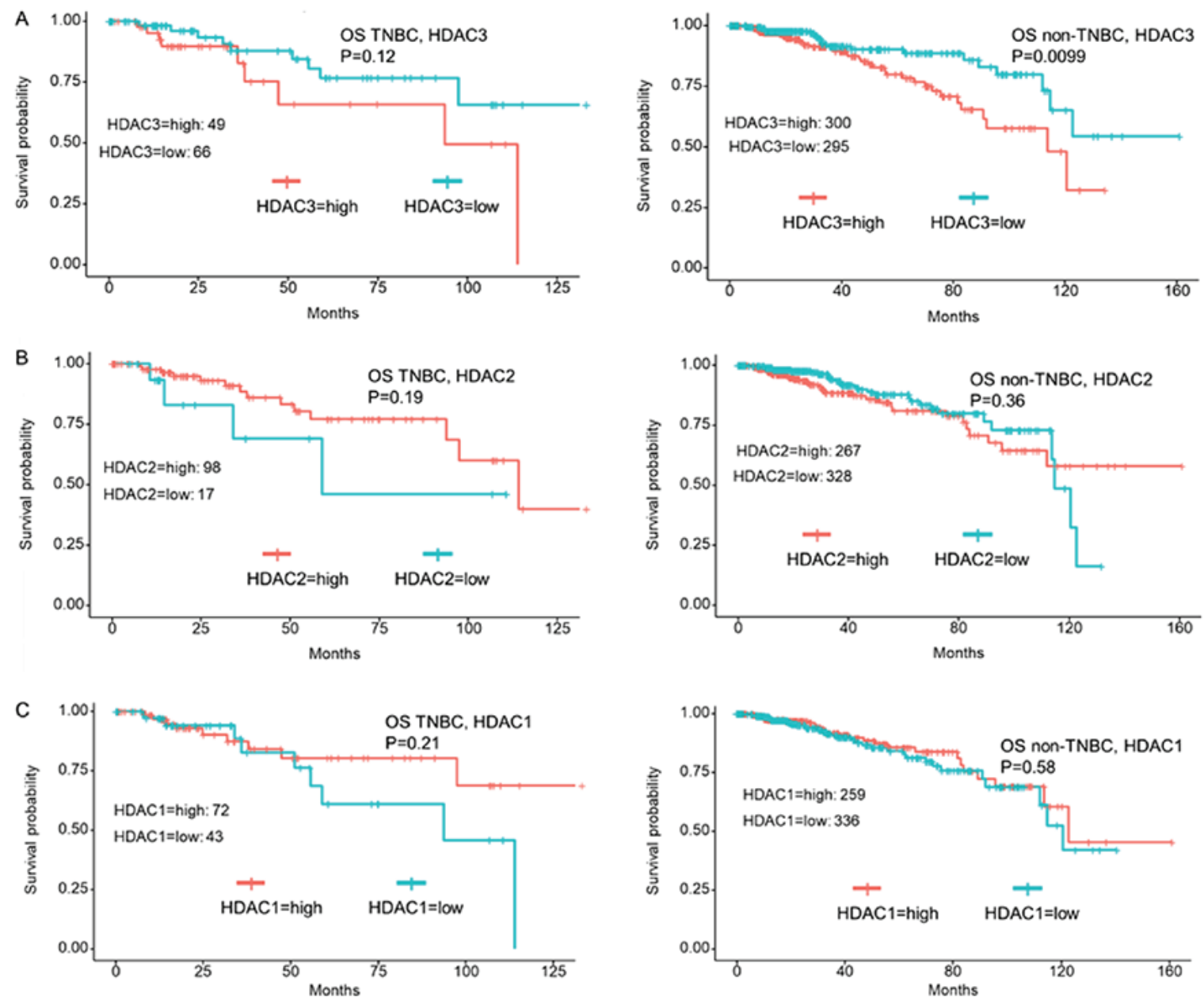

Figure 6. HDACs 1, 2, 3 expression and overall patient survival in breast cancer. The Cancer Genome Atlas (TCGA) breast cancer patient cohort gene expression data was analyzed for the TNBC subpopulation group and non-TNBC group for (A) HDAC3, (B) HDAC2, and (C) HDAC1 mRNA expression levels for overall survival (OS) rates. Kaplan-Meier plots showing the survival rate comparison between breast cancer patients who have high levels of HDACs 1, 2, 3 mRNA expression represent better survival $(\mathrm{P}<0.05)$ compared to a lower level of the expression of these genes $(\mathrm{A}-\mathrm{C})$. TNBC, triple-negative breast cancer; VM, vasculogenic mimicry.

both transcriptional induction and repression (75). We then wished to examine whether entinostat affects the expression of cancer stem cell marker genes, such as CD44, ALDH1 and COX-2 in VM-forming cells. The data revealed that entinostat significantly enhanced the expression levels of CD44, ALDH1 and COX-2 (Fig. 5D, F and G), whereas it reduced ALKBH5 expression in these experiments (Fig. 5E). The overexpression of COX-2 has been shown to be associated with the aggressiveness and invasive potential of tumor cells via several mechanisms (77). One of the mechanisms modulated by COX-2 is the increased production of VEGF and IL-8 $(78,79)$. However, in this study, we observed that treatment of the TNBC VM phenotype cells with entinostat reduced the expression of VEGFA. Thus, our argument is that the increased transcript level of COX-2 may be associated with more aggressiveness and may be linked to a higher expression of cancer stem cell-related genes (Fig. 5), which is in agreement with findings of recent studies $(80,81)$.

Breast cancer patients with a high expression of tumor suppressor or anti-angiogenesis-related genes have a better OS. HDAC2, but not HDAC1 expression is associated with a shorter OS of breast cancer patients (82). In agreement with published data (60), our METABRIC gene expression data analysis revealed that there was no significant prognostic relevance of HDAC1, HDAC2 and HDAC3 in TNBC compared with non-TNBC breast cancer patients (data not shown). However, TCGA breast cancer gene expression data analysis revealed that non-TNBC patients with a high HDAC3 expression had a shorter OS; however, this was not observed in TNBC patients (Fig. 6A). Furthermore, data analysis revealed that HDAC2 and HDAC1 expression do not have significant any effect on the OS of breast cancer patients (Fig. 6B and C).

It has already been established that genes related to the angiogenesis pathway are associated with the poor survival of breast cancer patients $(83,84)$. The expression of EMT-related genes, including Vimentin and $\beta$-catenin, along with CSC-related genes, predict poor a OS in breast cancer $(85,86)$. Tumor suppressors, such as PTEN can reverse EMT and the cancer stem cell phenotype in breast cancer (87).

Since our data conceded that entinostat treatment led to the re-expression of tumor suppressor and anti-angiogenesis-related genes accompanied by the abolition of VM structures, we then wished to examine whether these genes are associated with the survival of breast cancer patient. METABRIC cohort gene expression data analysis revealed that a high expression 

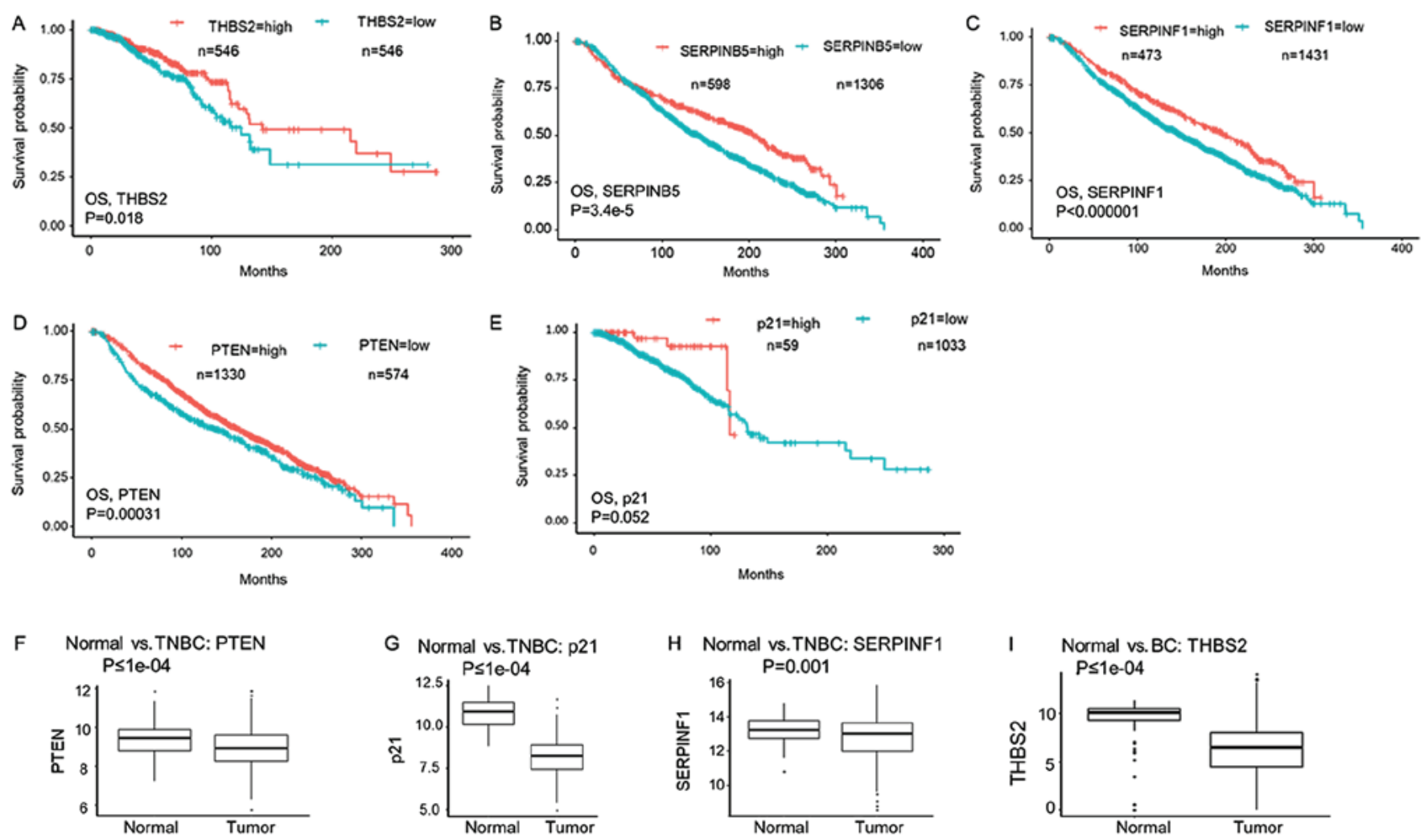

Figure 7. Breast cancer patients who have a high expression of tumor suppressors or anti-angiogenesis-related genes expression have a significantly better overall survival (OS). TCGA breast cancer cohort of 1092 patients' gene expression data was analyzed for (A) THBS2 and (E) p21 mRNA expressions for OS rates. Molecular Taxonomy of Breast Cancer International Consortium (METABRIC) cohort of 1,904 patient gene expression data also used to analyze for (B) SRPINF1, (C) SERPINB5, and (D) PTEN expressions for OS rates. Kaplan-Meier plots showing the survival rate comparison between breast cancer patients who have high mRNA expression levels of the anti-angiogenesis-related genes, THBS2, SERPINF1 and SERPINB5, and the tumor suppressor gene, PTEN, exhibit a better survival $(\mathrm{P}<0.05)$ compared to a lower expression level of these genes $(\mathrm{A}-\mathrm{D})$. Tumor suppressors or anti-angiogenesis genes are suppressed in TNBC: Expression levels of (F) PTEN, (G) p21, (H) SERPINF1, and (I) THBS2 genes were compared between normal as pooled samples and a TNBC subpopulation of patient samples (F-H), or all breast cancers (I) in the TCGA breast cancer cohort gene expression data. The Mann-Whitney U test was used to examine whether there was a difference in gene expression between normal and tumor samples. TNBC, triple-negative breast cancer; VM, vasculogenic mimicry.

of the SERPINF1, SERPINB5 and PTEN genes was significantly associated with a better survival of breast cancer patients (Fig. 7B-D). Furthermore, TCGA breast cancer cohort gene expression data analysis suggested that the expression of the anti-angiogenesis-related gene, THBS2, was significantly associated with a better OS of breast cancer patients (Fig. 7A). In agreement with the findings of a previous study (88), our data suggested that there was no significant association between the expression of $\mathrm{p} 21$ and the survival of breast cancer patients (Fig. 7E).

Subsequently, using the TCGA breast cancer cohort, we wished to examine whether tumor suppressor and anti-angiogenesis gene expression levels were reduced in TNBC patients compared the to the controls. The data revealed that the expression levels of PTEN (Fig. 7F), p21 (Fig. 7G), SERPINF1 (Fig. 7H) in TNBC and THBS2 (Fig. 7I) in all breast cancer patients were significantly reduced compared to the pooled normal tissue samples.

\section{Discussion}

TNBCs account for approximately 10 to $20 \%$ of all breast cancer cases and are characterized by the lack of expression of ER, PR and HER2 expression. TNBC is an aggressive subtype of breast cancer and exhibits resistance to conventional hormonal therapies, and is associated with poor prognosis, partly due to an enrichment of cancer stem cells (89).

Angiogenesis therapy failed to treat TNBC because it becomes resistant to the therapy and metastasize partly via VM formation (21). VM is a newly identified contrivance in the cancer progression and metastases field and we are just beginning to understanding the molecular regulation of VM formation in aggressive cancer. Tumor VM formation is recognized as an unfavorable prognostic indicator in patients with breast cancer (22). Breast cancers are heterogeneous in nature and particularly intrinsic heterogeneity in TNBC make them more aggressive $(18,23)$. Our VM formation data revealed that aggressive TNBC cells form approximately 70-80\% VM compared to luminal non-aggressive MCF-7 cells which form $100 \%$ tumrspeheres in the 3D Matrigel preclinical culture setting. Since TNBC cells have $>90 \%$ cancer stem cell positive characteristics, the data revealed that stem cell-positive TNBC cells form VM. Various molecules have been found to be involved in VM formation and can be targeted for therapy. Since CD44 has been shown to be involved in VM formation (50), we examined CD44 expression in TNBC VM-forming cells. Our data revealed that TNBC cells which formed VM, but not tumorspheres, were positive for CD44. In addition, we found that VM-forming cells were positive for VEGF-A and HIF-1 $\alpha$, and CD34, an 
endothelial cell marker. Since VM is associated with the angiogenic pathway in TNBC cells $(55,56)$, our data revealed that the expression levels of major angiogenic proteins, such as VEGF, ANG, IL-8, TIMP1 and TIMP2 were upregulated in the TNBC cell VM-medium (Fig. 2E-H). Our data also suggested that a few important tumor microenvironment mediators, such as IFN- $\gamma$ and MCP-1, found to be associated with tumor metastases $(90,91)$, upregulated in the TNBC cell VM medium (Fig. 2E-H). These results support the aggressive and metastatic features of TNBC.

The pan HDAC inhibitor, suberoylanilide hydroxamic acid (SAHA, vorinostat) has undergone clinical phase II trials for the treatment of solid cancers, including breast cancer with the most common side-effects encountered being fatigue, diarrhea and nausea $(92,93)$. Class I HDACs, particularly nuclear localized HDACs 1, 2, 3, have been found to be overexpressed in breast cancer (60), as well as in this study (Fig. 3A and B). A specific inhibitor of these HDACs, entinostat, has undergone clinical phase II trials for the treatment of solid cancers, including advanced breast cancer and is well tolerated $(94,95)$. HDAC signaling induces angiogenesis via the negative regulation of tumor suppressor genes (62). Recent studies have also suggested that tumor suppressor and angiogenesis inhibitor genes are downregulated when VMs are formed (9). In 2015, Liu et al reported that HDAC3 activity was essential for VM formation in glioma (64). In this study, although HDACs 1,2,3 were found to be overexpressed in TNBC cells (Fig. 3A and B), the expression of these HDACs was not found to be significantly associated with the OS of TNBC patients (Fig. 6). A phase II study demonstrated that the addition of entinostat to exemestane improved the OS of patients with advanced ER-positive breast cancer failing an aromatase inhibitor (96). Biomarker analysis has also revealed that patients who present with the hyperacetylation of lysines induced by HDAC inhibitors in blood samples have a reduced risk of disease progression. Apart from the nuclear histone and non-histone protein acetylation and the regulation of epigenetic gene expression, entinostat has almost no effect on major cancer cell signaling pathways, including PI3K/AKT, MAPKs and STAT3 (97,98), as also demonstrated herein (Fig. 4A).

We thus hypothesized that treatment with entinostat, a specific HDACs 1, 2, 3 inhibitor, leads to the epigenetic re-expression of downregulated tumor suppressor and anti-angiogenesis/angiogenesis inhibitor genes in TNBC to abolish VM structures. In this study, we found that entinostat was very effective in reducing the VM tube length of various aggressive TNBC cells in a 3D Matrigel cell culture model (Fig. 3C-E). Furthermore, treatment of the TNBC VM-forming cells with entinostat significantly enhanced the expression of tumor suppressor genes, such as p21, PTEN and APC (Fig. 4B-D) and enhanced the levels of anti-angiogenesis-related genes, such as THBS2, SERPINF1 and SERPINB5 (Fig. 4E-G). These data are in agreement with previously published data demonstrating that the tumor suppressor, PTEN, is silenced in a number of human cancers $(32,74,99)$ and one of the pan HDAC inhibitors namely, trichostatin A (TSA), potentiates doxorubicin-induced apoptosis by upregulating PTEN expression (100).

Our data also revealed that the levels of the angiogenesis inhibitor genes, THBS1 (Fig. 4I) and TIMP-1 (Fig. 4H), were markedly reduced following treatment of TNBC cells with the VM phenotype with entinostat through an unknown mechanism.

The angiogenesis-related genes, semaphorin 4D and integrin $\beta 5$, contribute to breast tumorigenic potential through survival signaling pathways $(101,102)$. A recent study suggested that SAHA exerts anti-cancer effects on highly aggressive pancreatic cancer cells and reduces VM formation through the inhibition of semaphorin 4D and integrin $\beta 5$ genes (68). In agreement with these data, our data revealed that the expression levels of the pro-angiogenesis gene, VEGF-A, the EMT-related genes, Vimentin and $\beta$-catenin (Fig. 5A-C), and the cancer stem cell-related gene, ALKBH5 (Fig. 5E), were significantly downregulated in the TNBC VM-forming cells following treatment with entinostat.

A previous study demonstrated that pan-HDAC inhibitors induce COX-2 expression in lung cancer cells, leading to a stimulation of endothelial cell proliferation (103). Furthermore, the HDACs 1,2,3 inhibitor entinostat, has been shown to enhance $\mathrm{COX}-2$ transcription via $\mathrm{NF}-\kappa \mathrm{B}$ activation in human pancreatic ductal adenocarcinoma BxPC-3 cells (104). In agreement with these publications, our data revealed that entinostat treatment significantly enhanced COX-2 transcript levels (Fig. 5G). The TGF- $\beta$ downstream target of COX-2 regulates TNBC stem cell properties (80). Considering previous findings that COX-2 expression is associated with the cancer stem cell marker gene expression $(80,81)$, our data revealed that entinostat enhanced COX-2 expression which may upregulate CD44 (Fig. 5D) and ALDH1 (Fig. 5F) expression in TNBC cells with the VM phenotype, which potentiates metastatic features.

The mechanisms through which the epigenetic drug, entinostat, reduces the transcription of genes remain unknown. HDAC inhibitors enhance the acetylation of histone and non-histone protein lysine residues, including transcription factors, by blocking the dynamic deacetylation pathway, which may be one of the reasons for the enhancement or downregulation of gene transcription (105). Further studies are required in order to elucidate the complex epigenetic regulation of gene transcription by HDACs 1, 2, 3 inhibition.

Since angiogenesis- and EMT pathway-related genes are associated with the poor survival of breast cancer patient $(83,84)$, we wished to examine whether the expression of tumor suppressor and anti-angiogenesis-related genes are associated with the better survival of breast cancer patients. We took advantage of breast cancer patient sample data analysis of two large gene expression cohorts, METABRIC and TCGA. Our data revealed that the increased mRNA expression of THBS2, SERPINF1, SERPINB5 and PTEN, but not that of p21, was associated with the better OS of breast cancer patients (Fig. 7A-E). When we compared the mRNA expression levels of the tumor suppressors, PTEN (Fig. 7F) and p21 (Fig. 7G), and those of the angiogenesis inhibitor gene, SERPINF1 (Fig. 7H), but not the THBS2 gene (Fig. 7I) between normal and TNBC subpopulation in TCGA data, we found that the levels of these genes were significantly downregulated in TNBC compared to pooled normal samples.

In conclusion, the findings of this study suggest that the VM phenotype arises in a subpopulation of cells from a conserved transcriptional response in a 3D Matrigel environment. The epigenetic re-expression of tumor suppressor and angiogenesis inhibitor genes through the inhibition of HDACs 1, 2, 3 may 
provide to be a strategy with which to control VM formation in TNBC cells.

\section{Acknowledgements}

The authors would like to thank Dr J. Ebos (Roswell Park Comprehensive Cancer Center) for providing the breast cancer lung metastatic LM2-4 cell line and Dr S. Patnaik (Roswell Park Comprehensive Cancer Center) for the MCF10A cell line.

\section{Funding}

This study was supported by the Roswell Park Health Research Incorporated (HRI) Start Up Funds \#714084-01 (NCH). This study was also supported by an NCI Grant P30CA016056 involving the use of Roswell Park Cancer Institute's Bioinformatics and Biostatistics Shared Resources.

\section{Availability of data and materials}

All data generated or analyzed during this study are included in this published article.

\section{Authors' contributions}

AMperformed the experiments and contributed to the conception, design, data analysis and progress of the work and writing the first draft of the manuscript. QQ, XP and LY performed the breast cancer TCGA and METABRIC OS data analysis and contributed to statistical data analysis. KT contributed to data analysis and prepared the manuscript with $\mathrm{AM}$ and $\mathrm{NCH}$. $\mathrm{NCH}$ contributed to the conception, design, data analysis, and writing of the final manuscript. All authors contributed to manuscript revision and discussion. All authors have read and approved the final manuscript.

\section{Ethics approval and consent to participate}

Not applicable.

\section{Patient consent for publication}

Not applicable.

\section{Competing interests}

The authors declare that they have no competing interests.

\section{References}

1. Hanahan D and Weinberg RA: Hallmarks of cancer: The next generation. Cell 144: 646-674, 2011.

2. Gacche RN: Compensatory angiogenesis and tumor refractoriness. Oncogenesis 4: e153, 2015.

3. Pinto MP, Sotomayor P, Carrasco-Avino G, Corvalan AH and Owen GI: Escaping antiangiogenic therapy: Strategies employed by cancer cells. Int J Mol Sci 17: E1489, 2016.

4. Maniotis AJ, Folberg R, Hess A, Seftor EA, Gardner LM, Pe'er J, Trent JM, Meltzer PS and Hendrix MJ: Vascular channel formation by human melanoma cells in vivo and in vitro: Vasculogenic mimicry. Am J Pathol 155: 739-752, 1999.

5. Plate KH, Scholz A and Dumont DJ: Tumor angiogenesis and anti-angiogenic therapy in malignant gliomas revisited. Acta Neuropathol 124: 763-775, 2012.
6. Folberg R and Maniotis AJ: Vasculogenic mimicry. APMIS 112: 508-525, 2004.

7. Folberg R, Hendrix MJ and Maniotis AJ: Vasculogenic mimicry and tumor angiogenesis. Am J Pathol 156: 361-381, 2000.

8. Clemente M, Pérez-Alenza MD, Illera JC and Peña L: Histological, immunohistological, and ultrastructural description of vasculogenic mimicry in canine mammary cancer. Vet Pathol 47: 265-274, 2010.

9. Seftor RE, Hess AR, Seftor EA, Kirschmann DA, Hardy KM, Margaryan NV and Hendrix MJ: Tumor cell vasculogenic mimicry: From controversy to therapeutic promise. Am J Pathol 181: 1115-1125, 2012.

10. Kirschmann DA, Seftor EA, Hardy KM, Seftor RE and Hendrix MJ: Molecular pathways: vasculogenic mimicry in tumor cells: diagnostic and therapeutic implications. Clin Cancer Res 18: 2726-2732, 2012.

11. Shirakawa K, Tsuda H, Heike Y, Kato K, Asada R, Inomata M, Sasaki H, Kasumi F, Yoshimoto M, Iwanaga T, et al: Absence of endothelial cells, central necrosis, and fibrosis are associated with aggressive inflammatory breast cancer. Cancer Res 61: 445-451, 2001.

12. Sood AK, Seftor EA, Fletcher MS, Gardner LM, Heidger PM, Buller RE, Seftor RE and Hendrix MJ: Molecular determinants of ovarian cancer plasticity. Am J Pathol 158: 1279-1288, 2001.

13. Sood AK, Fletcher MS, Zahn CM, Gruman LM, Coffin JE, Seftor EA and Hendrix MJ: The clinical significance of tumor cell-lined vasculature in ovarian carcinoma: Implications for anti-vasculogenic therapy. Cancer Biol Ther 1: 661-664, 2002.

14. Sharma N, Seftor RE, Seftor EA, Gruman LM, Heidger PM Jr, Cohen MB, Lubaroff DM and Hendrix MJ: Prostatic tumor cell plasticity involves cooperative interactions of distinct phenotypic subpopulations: Role in vasculogenic mimicry. Prostate 50: 189-201, 2002.

15. Passalidou E, Trivella M, Singh N, Ferguson M, Hu J, Cesario A, Granone P, Nicholson AG, Goldstraw P, Ratcliffe C, et al: Vascular phenotype in angiogenic and non-angiogenic lung non-small cell carcinomas. Br J Cancer 86: 244-249, 2002.

16. Yue WY and Chen ZP: Does vasculogenic mimicry exist in astrocytoma? J Histochem Cytochem 53: 997-1002, 2005.

17. Sun B, Zhang D, Zhang S, Zhang W, Guo H and Zhao X: Hypoxia influences vasculogenic mimicry channel formation and tumor invasion-related protein expression in melanoma. Cancer Lett 249: 188-197, 2007.

18. Bianchini G, Balko JM, Mayer IA, Sanders ME and Gianni L: Triple-negative breast cancer: Challenges and opportunities of a heterogeneous disease. Nat Rev Clin Oncol 13: 674-690, 2016.

19. Bayraktar S and Glück S: Molecularly targeted therapies for metastatic triple-negative breast cancer. Breast Cancer Res Treat 138: 21-35, 2013

20. Ribatti D, Nico B, Ruggieri S, Tamma R, Simone G and Mangia A: Angiogenesis and antiangiogenesis in triple-negative breast cancer. Transl Oncol 9: 453-457, 2016.

21. Sun H, Zhang D, Yao Z, Lin X, Liu J, Gu Q, Dong X, Liu F, Wang Y, Yao N, et al: Anti-angiogenic treatment promotes triple-negative breast cancer invasion via vasculogenic mimicry. Cancer Biol Ther 18: 205-213, 2017.

22. Shen Y, Quan J, Wang M, Li S, Yang J, Lv M, Chen Z, Zhang L, Zhao $\mathrm{X}$ and Yang J: Tumor vasculogenic mimicry formation as an unfavorable prognostic indicator in patients with breast cancer. Oncotarget 8: 56408-56416, 2017.

23. Shao F, Sun H and Deng CX: Potential therapeutic targets of triple-negative breast cancer based on its intrinsic subtype. Oncotarget 8: 73329-73344, 2017.

24. Qi L, Song W, Liu Z, Zhao X, Cao W and Sun B: Wnt3a promotes the vasculogenic mimicry formation of colon cancer via Wnt/beta-catenin signaling. Int J Mol Sci 16: 18564-18579, 2015.

25. Liu Z, Sun B, Qi L, Li H, Gao J and Leng X: Zinc finger E-box binding homeobox 1 promotes vasculogenic mimicry in colorectal cancer through induction of epithelial-to-mesenchymal transition. Cancer Sci 103: 813-820, 2012.

26. Demou ZN and Hendrix MJ: Microgenomics profile the endogenous angiogenic phenotype in subpopulations of aggressive melanoma. J Cell Biochem 105: 562-573, 2008.

27. Su M, Feng YJ, Yao LQ, Cheng MJ, Xu CJ, Huang Y, Zhao YQ and Jiang H: Plasticity of ovarian cancer cell SKOV3ip and vasculogenic mimicry in vivo. Int J Gynecol Cancer 18: 476-486, 2008.

28. Xu B,Li J,Liu X,Li C and Chang X: TXNDC5 is a cervical tumor susceptibility gene that stimulates cell migration, vasculogenic mimicry and angiogenesis by down-regulating SERPINF1 and TRAF1 expression. Oncotarget 8: 91009-91024, 2017. 
29. Bittner M, Meltzer P, Chen Y, Jiang Y, Seftor E, Hendrix M, Radmacher M, Simon R, Yakhini Z, Ben-Dor A, et al: Molecular classification of cutaneous malignant melanoma by gene expression profiling. Nature 406: 536-540, 2000.

30. Li M, Edamatsu H, Kitazawa R, Kitazawa S and Kataoka T: Phospholipase Cepsilon promotes intestinal tumorigenesis of Apc(Min/+) mice through augmentation of inflammation and angiogenesis. Carcinogenesis 30: 1424-1432, 2009.

31. Wu S, Yu L, Cheng Z, Song W, Zhou L and Tao Y: Expression of maspin in non-small cell lung cancer and its relationship to vasculogenic mimicry. J Huazhong Univ Sci Technolog Med Sci 32: 346-352, 2012.

32. Mirmohammadsadegh A, Marini A, Nambiar S, Hassan M, Tannapfel A, Ruzicka T and Hengge UR: Epigenetic silencing of the PTEN gene in melanoma. Cancer Res 66: 6546-6552, 2006.

33. Li Y, Chen H, Hardy TM and Tollefsbol TO: Epigenetic regulation of multiple tumor-related genes leads to suppression of breast tumorigenesis by dietary genistein. PLoS One 8: e54369, 2013.

34. Hu E, Dul E, Sung CM, Chen Z, Kirkpatrick R, Zhang GF, Johanson K, Liu R, Lago A, Hofmann G, et al: Identification of novel isoform-selective inhibitors within class I histone deacetylases. J Pharmacol Exp Ther 307: 720-728, 2003.

35. Vannini A, Volpari C, Filocamo G, Casavola EC, Brunetti M, Renzoni D, Chakravarty P, Paolini C, De Francesco R, Gallinari P, et al: Crystal structure of a eukaryotic zinc-dependent histone deacetylase, human HDAC8, complexed with a hydroxamic acid inhibitor. Proc Natl Acad Sci USA 101: 15064-15069, 2004.

36. Inoue S, Mai A, Dyer MJ and Cohen GM: Inhibition of histone deacetylase class I but not class II is critical for the sensitization of leukemic cells to tumor necrosis factor-related apoptosis-inducing ligand-induced apoptosis. Cancer Res 66: 6785-6792, 2006.

37. Bracker TU, Sommer A, Fichtner I, Faus H, Haendler B and Hess-Stumpp H: Efficacy of MS-275, a selective inhibitor of class I histone deacetylases, in human colon cancer models. Int J Oncol 35: 909-920, 2009 .

38. Ryan QC, Headlee D, Acharya M, Sparreboom A, Trepel JB Ye J, Figg WD, Hwang K, Chung EJ, Murgo A, et al: Phase I and pharmacokinetic study of MS-275, a histone deacetylase inhibitor, in patients with advanced and refractory solid tumors or lymphoma. J Clin Oncol 23: 3912-3922, 2005.

39. Shah P, Gau Y and Sabnis G: Histone deacetylase inhibitor entinostat reverses epithelial to mesenchymal transition of breast cancer cells by reversing the repression of E-cadherin. Breast Cancer Res Treat 143: 99-111, 2014

40. Schech A, Kazi A, Yu S, Shah P and Sabnis G: Histone deacetylase inhibitor entinostat inhibits tumor-initiating cells in triple-negative breast cancer cells. Mol Cancer Ther 14: $1848-1857,2015$

41. Gangavarapu KJ, Azabdaftari G, Morrison CD, Miller A, Foster BA and Huss WJ: Aldehyde dehydrogenase and ATP binding cassette transporter $\mathrm{G} 2$ (ABCG2) functional assays isolate different populations of prostate stem cells where ABCG2 function selects for cells with increased stem cell activity. Stem Cell Res Ther 4: 132, 2013

42. Maiti A, Takabe K and Hait NC: Metastatic triple-negative breast cancer is dependent on SphKs/S1P signaling for growth and survival. Cell Signal 32: 85-92, 2017.

43. Livak KJ and Schmittgen TD: Analysis of relative gene expression data using real-time quantitative PCR and the 2(-Delta Delta C(T)) method. Methods 25: 402-408, 2001.

44. Tavallai M, Hamed HA, Roberts JL, Cruickshanks N Chuckalovcak J, Poklepovic A, Booth L and Dent P: Nexavar/ Stivarga and viagra interact to kill tumor cells. J Cell Physiol 230: 2281-2298, 2015

45. LeBlanc M, Jacobson J and Crowley J: Partitioning and peeling for constructing prognostic groups. Stat Methods Med Res 11: 247-274, 2002

46. Benton G, Arnaoutova I, George J, Kleinman HK and Koblinski J: Matrigel: From discovery and ECM mimicry to assays and models for cancer research. Adv Drug Deliv Rev 79-80: 3-18, 2014.

47. Izawa Y, Kashii-Magaribuchi K, Yoshida K, Nosaka M, Tsuji N, Yamamoto A, Kuroyanagi K, Tono K, Tanihata M, Imanishi $\mathrm{M}$, et al: Stem-like human breast cancer cells initiate vasculogenic mimicry on matrigel. Acta Histochem Cytochem 51: 173-183, 2018

48. Williamson SC, Metcalf RL, Trapani F, Mohan S, Antonello J, Abbott B, Leong HS, Chester CP, Simms N, Polanski R, et al: Vasculogenic mimicry in small cell lung cancer. Nat Commun 7: 13322,2016
49. Hendrix MJ, Seftor EA, Hess AR and Seftor RE: Vasculogenic mimicry and tumour-cell plasticity: Lessons from melanoma. Nat Rev Cancer 3: 411-421, 2003.

50. Paulis YW, Huijbers EJ, van der Schaft DW, Soetekouw PM, Pauwels P, Tjan-Heijnen VC and Griffioen AW: CD44 enhances tumor aggressiveness by promoting tumor cell plasticity. Oncotarget 6: 19634-19646, 2015.

51. Meyer MJ, Fleming JM, Ali MA, Pesesky MW, Ginsburg E and Vonderhaar BK: Dynamic regulation of CD24 and the invasive, CD44posCD24neg phenotype in breast cancer cell lines. Breast Cancer Res 11: R82, 2009.

52. Fillmore CM and Kuperwasser C: Human breast cancer cell lines contain stem-like cells that self-renew, give rise to phenotypically diverse progeny and survive chemotherapy. Breast Cancer Res 10: R25, 2008 .

53. Ricci-Vitiani L, Pallini R, Biffoni M, Todaro M, Invernici G, Cenci T, Maira G, Parati EA, Stassi G, Larocca LM, et al: Tumour vascularization via endothelial differentiation of glioblastoma stem-like cells. Nature 468: 824-828, 2010.

54. Aikins AR, Kim M, Raymundo B and Kim CW: Downregulation of transgelin blocks interleukin-8 utilization and suppresses vasculogenic mimicry in breast cancer cells. Exp Biol Med (Maywood) 242: 573-583, 2017.

55. Shirakawa K, Kobayashi H, Sobajima J, Hashimoto D, Shimizu A and Wakasugi H: Inflammatory breast cancer: Vasculogenic mimicry and its hemodynamics of an inflammatory breast cancer xenograft model. Breast Cancer Res 5: 136-139, 2003.

56. Basu GD, Liang WS, Stephan DA, Wegener LT, Conley CR, Pockaj BA and Mukherjee P: A novel role for cyclooxygenase-2 in regulating vascular channel formation by human breast cancer cells. Breast Cancer Res 8: R69, 2006.

57. Geng L, Chaudhuri A, Talmon G, Wisecarver JL and Wang J: TGF-Beta suppresses VEGFA-mediated angiogenesis in colon cancer metastasis. PLoS One 8: e59918, 2013.

58. Ferrari G, Cook BD, Terushkin V, Pintucci G and Mignatti P: Transforming growth factor-beta 1 (TGF-beta1) induces angiogenesis through vascular endothelial growth factor (VEGF)-mediated apoptosis. J Cell Physiol 219: 449-458, 2009.

59. Krusche CA, Wülfing $P$, Kersting C, Vloet A, Böcker W, Kiesel L, Beier HM and Alfer J: Histone deacetylase-1 and -3 protein expression in human breast cancer: A tissue microarray analysis. Breast Cancer Res Treat 90: 15-23, 2005.

60. Müller BM, Jana L, Kasajima A, Lehmann A, Prinzler J, Budczies J, Winzer KJ, Dietel M, Weichert W and Denkert C: Differential expression of histone deacetylases HDAC1, 2 and 3 in human breast cancer - overexpression of HDAC 2 and HDAC3 is associated with clinicopathological indicators of disease progression. BMC Cancer 13: 215, 2013

61. Minamiya Y, Ono T, Saito H, Takahashi N, Ito M, Mitsui M, Motoyama S and Ogawa J: Expression of histone deacetylase 1 correlates with a poor prognosis in patients with adenocarcinoma of the lung. Lung Cancer 74: 300-304, 2011.

62. Zhang Z, Yamashita H, Toyama T, Sugiura H, Ando Y, Mita K, Hamaguchi M, Hara Y, Kobayashi S and Iwase H: Quantitation of HDAC1 mRNA expression in invasive carcinoma of the breast*. Breast Cancer Res Treat 94: 11-16, 2005.

63. Kim MS, Kwon HJ, Lee YM, Baek JH, Jang JE, Lee SW, Moon EJ, Kim HS, Lee SK, Chung HY, et al: Histone deacetylases induce angiogenesis by negative regulation of tumor suppressor genes. Nat Med 7: 437-443, 2001.

64. Liu X, Wang JH, Li S, Li LL, Huang M, Zhang YH, Liu Y, Yang YT, Ding R and Ke YQ: Histone deacetylase 3 expression correlates with vasculogenic mimicry through the phosphoinositide3-kinase/ERK-MMP-laminin5 $\gamma 2$ signaling pathway. Cancer Sci 106: 857-866, 2015.

65. Knipstein J and Gore L: Entinostat for treatment of solid tumors and hematologic malignancies. Expert Opin Investig Drugs 20: $1455-1467,2011$

66. Merino VF, Nguyen N, Jin K, Sadik H, Cho S, Korangath P, Han L, Foster YM, Zhou XC, Zhang Z, et al: Combined treatment with epigenetic, differentiating, and chemotherapeutic agents cooperatively targets tumor-initiating cells in triple-negative breast cancer. Cancer Res 76: 2013-2024, 2016.

67. Min A, Im SA, Kim DK, Song SH, Kim HJ, Lee KH, Kim TY, Han SW, Oh DY, Kim TY, et al: Histone deacetylase inhibitor, suberoylanilide hydroxamic acid (SAHA), enhances anti-tumor effects of the poly (ADP-ribose) polymerase (PARP) inhibitor olaparib in triple-negative breast cancer cells. Breast Cancer Res 17: 33, 2015. 
68. Xu XD, Yang L, Zheng LY, Pan YY, Cao ZF, Zhang ZQ, Zhou QS, Yang B and Cao C: Suberoylanilide hydroxamic acid, an inhibitor of histone deacetylase, suppresses vasculogenic mimicry and proliferation of highly aggressive pancreatic cancer PaTu8988 cells. BMC Cancer 14: 373, 2014.

69. Trapani D, Esposito A, Criscitiello C, Mazzarella L, Locatelli M, Minchella I, Minucci S and Curigliano G: Entinostat for the treatment of breast cancer. Expert Opin Investig Drugs 26: 965-971, 2017.

70. Shi HY, Liang R, Templeton NS and Zhang M: Inhibition of breast tumor progression by systemic delivery of the maspin gene in a syngeneic tumor model. Mol Ther 5: 755-761, 2002.

71. Ikenaka Y, Yoshiji H, Kuriyama S, Yoshii J, Noguchi R, Tsujinoue H, Yanase K, Namisaki T, Imazu H, Masaki T, et al: Tissue inhibitor of metalloproteinases-1 (TIMP-1) inhibits tumor growth and angiogenesis in the TIMP-1 transgenic mouse model. Int J Cancer 105: 340-346, 2003.

72. Yoshiji H, Kuriyama S, Yoshii J, Ikenaka Y, Noguchi R, Nakatani T, Tsujinoue H, Yanase K, Namisaki T, Imazu H, et al: Tissue inhibitor of metalloproteinases-1 attenuates spontaneous liver fibrosis resolution in the transgenic mouse. Hepatology 36: 850-860, 2002.

73. Lawler J: Thrombospondin-1 as an endogenous inhibitor of angiogenesis and tumor growth. J Cell Mol Med 6: 1-12, 2002.

74. Zhou XP, Gimm O, Hampel H, Niemann T, Walker MJ and Eng C: Epigenetic PTEN silencing in malignant melanomas without PTEN mutation. Am J Pathol 157: 1123-1128, 2000.

75. Chueh AC, Tse JW, Tögel L and Mariadason JM: Mechanisms of histone deacetylase inhibitor-regulated gene expression in cancer cells. Antioxid Redox Signal 23: 66-84, 2015

76. Aoki K and Taketo MM: Adenomatous polyposis coli (APC): A multi-functional tumor suppressor gene. J Cell Sci 120 3327-3335, 2007.

77. Rozic JG, Chakraborty C and Lala PK: Cyclooxygenase inhibitors retard murine mammary tumor progression by reducing tumor cell migration, invasiveness and angiogenesis. Int $\mathrm{J}$ Cancer 93: 497-506, 2001.

78. Gallo O, Franchi A, Magnelli L, Sardi I, Vannacci A, Boddi V, Chiarugi V and Masini E: Cyclooxygenase-2 pathway correlates with VEGF expression in head and neck cancer. Implications for tumor angiogenesis and metastasis. Neoplasia 3: 53-61, 2001.

79. Kuwano T, Nakao S, Yamamoto H, Tsuneyoshi M, Yamamoto T, Kuwano $\mathrm{M}$ and Ono M: Cyclooxygenase 2 is a key enzyme for inflammatory cytokine-induced angiogenesis. FASEB J 18 300-310, 2004

80. Tian J, Hachim MY, Hachim IY, Dai M, Lo C, Raffa FA, Ali S and Lebrun JJ: Cyclooxygenase-2 regulates TGF $\beta$-induced cancer stemness in triple-negative breast cancer. Sci Rep 7: 40258, 2017.

81. Liu S, Zhang C, Zhang K, Gao Y, Wang Z, Li X, Cheng G, Wang S, Xue X, Li W, et al: FOXP3 inhibits cancer stem cell self-renewal via transcriptional repression of COX2 in colorectal cancer cells. Oncotarget 8: 44694-44704, 2017.

82. Zhao H, Yu Z, Zhao L, He M, Ren J, Wu H, Chen Q, Yao W and Wei M: HDAC2 overexpression is a poor prognostic factor of breast cancer patients with increased multidrug resistance-associated protein expression who received anthracyclines therapy. Jpn J Clin Oncol 46: 893-902, 2016.

83. Sa-Nguanraksa D, Chuangsuwanich T, Pongpruttipan T and $\mathrm{O}$-Charoenrat P: High vascular endothelial growth factor gene expression predicts poor outcome in patients with non-luminal A breast cancer. Mol Clin Oncol 3: 1103-1108, 2015

84. Ramanathan R, Olex AL, Dozmorov M, Bear HD, Fernandez LJ and Takabe K: Angiopoietin pathway gene expression associated with poor breast cancer survival. Breast Cancer Res Treat 162: 191-198, 2017.

85. Liu F, Gu LN, Shan BE, Geng CZ and Sang MX: Biomarkers for EMT and MET in breast cancer: An update. Oncol Lett 12 4869-4876, 2016.

86. Patel NA, Patel PS and Vora HH: Role of PRL-3, Snail, Cytokeratin and Vimentin expression in epithelial mesenchyma transition in breast carcinoma. Breast Dis 35: 113-127, 2015.

87. Han M, Liu M, Wang Y, Chen X, Xu J, Sun Y, Zhao L, Qu H, Fan Y and Wu C: Antagonism of miR-21 reverses epithelial-mesenchymal transition and cancer stem cell phenotype through AKT/ERK1/2 inactivation by targeting PTEN. PLoS One 7: e39520, 2012.

88. Pellikainen MJ, Pekola TT, Ropponen KM, Kataja VV, Kellokoski JK, Eskelinen MJ and Kosma VM: p21WAF1 expression in invasive breast cancer and its association with p53, AP-2, cell proliferation, and prognosis. J Clin Pathol 56: 214-220, 2003 .
89. Li X, Yang J, Peng L, Sahin AA, Huo L, Ward KC, O'Regan R, Torres MA and Meisel JL: Triple-negative breast cancer has worse overall survival and cause-specific survival than non-triple-negative breast cancer. Breast Cancer Res Treat 161: 279-287, 2017.

90. Mojic M, Takeda K and Hayakawa Y: The dark side of IFN-gamma: Its role in promoting cancer immunoevasion. Int J Mol Sci 19: E89, 2017.

91. Dutta P, Sarkissyan M, Paico K, Wu Y and Vadgama JV: $\mathrm{MCP}-1$ is overexpressed in triple-negative breast cancers and drives cancer invasiveness and metastasis. Breast Cancer Res Treat 170: 477-486, 2018

92. Gryder BE, Sodji QH and Oyelere AK: Targeted cancer therapy: Giving histone deacetylase inhibitors all they need to succeed. Future Med Chem 4: 505-524, 2012.

93. Kim HJ and Bae SC: Histone deacetylase inhibitors: Molecular mechanisms of action and clinical trials as anti-cancer drugs. Am J Transl Res 3: 166-179, 2011.

94. Connolly RM, Li H, Jankowitz RC, Zhang Z, Rudek MA, Jeter SC, Slater SA, Powers P, Wolff AC, Fetting JH, et al: Combination epigenetic therapy in advanced breast cancer with 5-azacitidine and entinostat: A phase II national cancer Institute/Stand up to cancer study. Clin Cancer Res 23: 2691-2701, 2017.

95. Connolly RM, Rudek MA and Piekarz R: Entinostat: A promising treatment option for patients with advanced breast cancer. Future Oncol 13: 1137-1148, 2017.

96. Yardley DA, Ismail-Khan RR, Melichar B, Lichinitser M, Munster PN, Klein PM, Cruickshank S, Miller KD Lee MJ and Trepel JB: Randomized phase II, double-blind, placebo-controlled study of exemestane with or without entinostat in postmenopausal women with locally recurrent or metastatic estrogen receptor-positive breast cancer progressing on treatment with a nonsteroidal aromatase inhibitor. J Clin Oncol 31: 2128-2135, 2013

97. Wang S, Zhu L, Zuo W, Zeng Z, Huang L, Lin F, Lin R, Wang J, Lu J, Wang Q, et al: MicroRNA-mediated epigenetic targeting of Survivin significantly enhances the antitumor activity of paclitaxel against non-small cell lung cancer. Oncotarget 7: 37693-37713, 2016.

98. Ni L, Wang L, Yao C, Ni Z, Liu F, Gong C, Zhu X, Yan X, Watowich SS, Lee DA, et al: The histone deacetylase inhibitor valproic acid inhibits NKG2D expression in natural killer cells through suppression of STAT3 and HDAC3. Sci Rep 7: 45266, 2017.

99. Kazanets A, Shorstova T, Hilmi K, Marques M and Witcher M: Epigenetic silencing of tumor suppressor genes: Paradigms, puzzles, and potential. Biochim Biophys Acta 1865: 275-288, 2016.

100. Pan L, Lu J, Wang X, Han L, Zhang Y, Han S and Huang B: Histone deacetylase inhibitor trichostatin a potentiates doxorubicin-induced apoptosis by up-regulating PTEN expression. Cancer 109: 1676-1688, 2007.

101. Jiang H, Chen C, Sun Q, Wu J, Qiu L, Gao C, Liu W, Yang J, Jun N and Dong J: The role of semaphorin 4D in tumor development and angiogenesis in human breast cancer. OncoTargets Ther 9: 5737-5750, 2016.

102. Bianchi-Smiraglia A, Paesante $S$ and Bakin AV: Integrin $\beta 5$ contributes to the tumorigenic potential of breast cancer cells through the Src-FAK and MEK-ERK signaling pathways. Oncogene 32: 3049-3058, 2013.

103. Wang X, Li G, Wang A, Zhang Z, Merchan JR and Halmos B: Combined histone deacetylase and cyclooxygenase inhibition achieves enhanced antiangiogenic effects in lung cancer cells. Mol Carcinog 52: 218-228, 2013.

104. Peulen O, Gonzalez A, Peixoto P, Turtoi A, Mottet D, Delvenne P and Castronovo V: The anti-tumor effect of HDAC inhibition in a human pancreas cancer model is significantly improved by the simultaneous inhibition of cyclooxygenase 2 . PLoS One 8: e75102, 2013.

105. New M, Olzscha H and La Thangue NB: HDAC inhibitor-based therapies: Can we interpret the code? Mol Oncol 6: 637-656, 2012 .

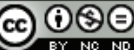

This work is licensed under a Creative Commons Attribution-NonCommercial-NoDerivatives 4.0 International (CC BY-NC-ND 4.0) License. 